\title{
Modified Pseudo-Dynamic Bearing Capacity of Shallow Foundations Subjected to Inclined- Eccentric Combined Loading
}

Maedeh Akhavan Tavakoli

University of Guilan

Hessam Fathipour

University of Guilan

Meghdad Payan

University of Guilan

Reza Jamshidi Chenari ( $\nabla$ jamshidi_reza@guilan.ac.ir)

University of Guilan https://orcid.org/0000-0002-7950-322X

Hadi Ahmadi

University of Guilan

\section{Research Article}

Keywords: Bearing capacity, Modified pseudo-dynamic, Combined loading, Lower bound, Finite element limit analysis (FELA), Second-order cone programming (SOCP)

Posted Date: January 28th, 2022

DOI: https://doi.org/10.21203/rs.3.rs-1281541/v1

License: (c) (1) This work is licensed under a Creative Commons Attribution 4.0 International License.

Read Full License 


\title{
Modified pseudo-dynamic bearing capacity of shallow foundations subjected to inclined-eccentric combined loading
}

\author{
Maedeh Akhavan Tavakoli ${ }^{1}$, Hessam Fathipour ${ }^{2}$, Meghdad Payan $^{3}$, Reza Jamshidi Chenari ${ }^{4} *$, Hadi Ahmadi ${ }^{5}$
}

\section{ABSTRACT}

1 Shallow foundations are commonly subjected to simultaneous inclined and eccentric combined

2 loadings exerted by the overlying superstructure and geo-environmental sources. The

3 performance of such footings in seismic-prone areas is a topic of great interest in geotechnical

4 engineering practice. In this paper, a comprehensive parametric study is conducted to evaluate

5 the seismic bearing capacity of shallow strip foundations overlying dry and cohesionless granular

6 soil under the action of vertical-horizontal-moment combined loading. For this purpose, a

7 systematic combination of the lower-bound theorems of the limit analysis, the finite element

8 method, and the nonlinear programming is implemented. The second-order cone programming

9 (SOCP) is adopted for efficient optimization purposes so as to model the actual nonlinear form

10 of the universal Mohr-Coulomb yield function. In addition, the equilibrium equations associated

11 with the combined loading are incorporated into the lower bound formulations. The seismic

12 condition is simulated by the well-established modified pseudo-dynamic approach by accounting

13 for the significant influence of phase difference as well as the primary and shear waves

14 propagation through applying non-uniform inertia forces along the vertical and horizontal

15 directions, respectively. The employed formulations are rigorously validated against a majority

\footnotetext{
${ }^{1}$ M.Sc. Student, Department of Civil Engineering, Faculty of Engineering, University of Guilan, Rasht, Iran. (maedehakhavan@ msc.guilan.ac.ir)

${ }^{2}$ M.Sc. Graduate, Department of Civil Engineering, Faculty of Engineering, University of Guilan, Rasht, Iran. (hessamfathipour@msc.guilan.ac.ir)

${ }^{3}$ Assistant Professor, Department of Civil Engineering, Faculty of Engineering, University of Guilan, Rasht, Iran. (payan@guilan.ac.ir)

${ }^{4}$ Postdoctoral Fellow, Faculty of Civil engineering, Royal Military College of Canada, Kingston, Ontario, Canada (*corresponding author: jamshidi@rmc.ca). $2^{\text {nd }}$ affiliation: Associate Professor, Department of Civil Engineering, Faculty of Engineering, University of Guilan, Rasht, Iran (Jamshidi_reza@ guilan.ac.ir).

${ }^{5}$ Assistant Professor, Department of Civil Engineering, Faculty of Engineering, University of Guilan, Rasht, Iran. (hadiahmadi@guilan.ac.ir)
} 
16 of high-quality studies in the literature in the static combined loading condition. The results of

17 the seismic bearing capacity are presented in the forms of spectral responses and failure

18 envelopes for the eccentric and inclined loadings. Accordingly, the influences of non-

19 dimensional frequency, induced seismic acceleration and material damping on the ultimate

20 bearing capacity of eccentrically and obliquely loaded strip footings are thoroughly examined

21 and discussed. The results show that the most critical responses of the shallow foundation are

22 captured in the resonance condition of earthquake excitation. As the seismic intensity decreases

23 and the damping ratio increases, the spectral vertical, horizontal and moment bearing capacities

24 of surface footings become smoother. In addition, the failure envelopes of the shallow

25 foundation subjected to either inclined or eccentric loading significantly shrink with the increase

26 in the earthquake accelerations and decrease in the material damping of the underlying soil mass.

27 The amount of changes in the size of failure envelopes in the normalized $V-H$ and $V-M$

28 spaces due to the variation of seismic intensity and material damping depends directly on the

29 non-dimensional frequency of the earthquake excitation.

30 Keywords: Bearing capacity; Modified pseudo-dynamic; Combined loading; Lower bound;

31 Finite element limit analysis (FELA); Second-order cone programming (SOCP)

\section{LIST OF NOTATIONS}
[A] Matrix of linear constraints
$\{\boldsymbol{b}\} \quad$ Vector of linear constraints
$\boldsymbol{A}^{\boldsymbol{e}} \quad$ The area of each triangular element
$\boldsymbol{a}_{\boldsymbol{h}} \quad$ Horizontal earthquake acceleration
$\boldsymbol{a}_{\boldsymbol{v}} \quad$ Vertical earthquake acceleration
$\boldsymbol{B} \quad$ Width of the footing
$\boldsymbol{C}_{\boldsymbol{p}}$ Coefficient of MPD approach for vertical earthquake acceleration
$\boldsymbol{C}_{\boldsymbol{p} \boldsymbol{z}} \quad$ Coefficient of MPD approach for vertical earthquake acceleration
$\boldsymbol{C}_{\boldsymbol{s}}$ Coefficient of MPD approach for horizontal earthquake acceleration
$\boldsymbol{C}_{\boldsymbol{s Z}} \quad$ Coefficient of MPD approach for horizontal earthquake acceleration 


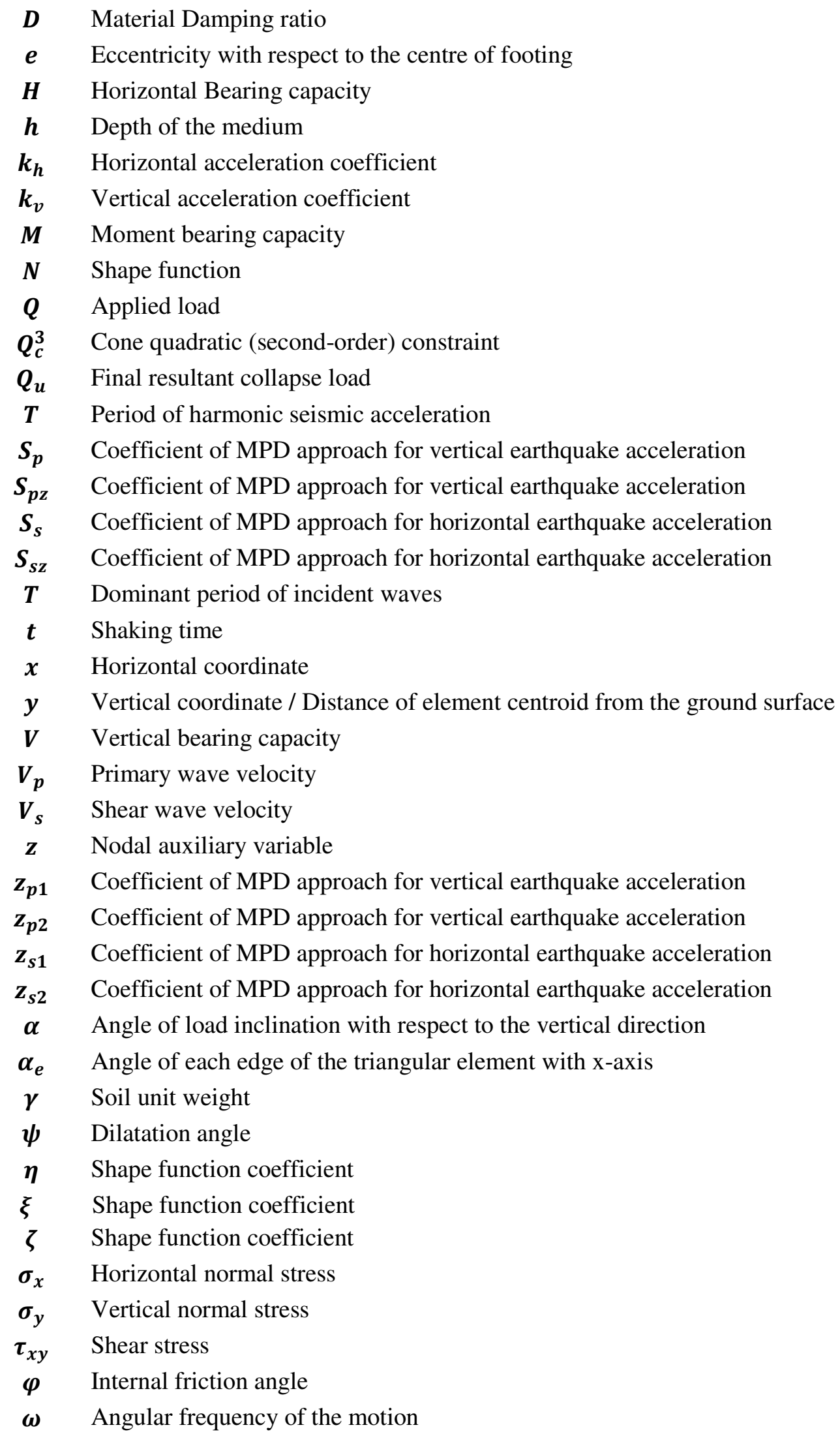




\section{INTRODUCTION}

33 According to the fierce demand for constructing a variety of infrastructures with stringent design

34 codes, the evaluation of the ultimate bearing capacity of shallow foundations subjected to

35 eccentric and inclined combined loading has received great attention amongst geotechnical

36 engineering community. Traditionally, most of the solutions to the bearing capacity problem

37 have been related to the ultimate sustainable vertical load which could be applied concentrically

38 to the strip footing (Jamshidi Chenari et al. 2014; Ranjbar Pouya et al. 2014; Jamshidi

39 Chenari and Mahigir 2014 \& 2017; Veiskarami et al. 2017; Pakdel et al. 2019; Jamshidi

40 Chenari et al. 2019; Foroutan Kalourazi et al. 2019; Izadi et al. 2019 \& 2021a).

41 As truly admitted by several researchers in most previous studies, a shallow foundation is rarely

42 subjected to solely vertical concentric load. However, it always experiences both inclined and

43 eccentric loadings which are applied by either the overlying superstructures self-weight or

44 various geo-environmental sources, such as earthquake, wind, wave forces, etc. The stability

45 analysis of shallow footings under the action of such loadings and their interactions turns out to

46 be far more complicated as compared to the vertical load bearing capacity assessment. To be

47 more specific, the relatively simple methods previously developed for the vertical bearing

48 capacity analysis would not lead to practically credible and theoretically meticulous solutions.

49 Several studies have been conducted throughout the literature to investigate the bearing capacity

50 of shallow foundations subjected to inclined concentric loading (Saran et al. 1971; Yahia-

51 Cherif et al. 2017; Zheng et al. 2018; Ouahab et al. 2020), vertical eccentric loading (Prakash

52 and Saran 1971; Purkayastha and Char 1977; Okamura et al. 2002; Taiebat and Carter

53 2002; Krabbenhoft et al. 2012; Sargazi and Hosseininia 2017; Pham et al. 2019), and

54 combined eccentric and inclined loading (Saran and Agrawal 1991; Bransby and Randolph 
al. 2020; Keawsawasvong et al. 2021).

57 In seismic-prone areas, the shallow foundations and the overlying structure may be subjected to 58 earthquake loading caused primarily by the seismic waves traveling through the earth layers

59 toward the ground surface. The seismic bearing capacity of shallow foundations subjected to

60 vertical loading has been the focus of numerous experimental, theoretical and numerical studies

61 in the past. Numerical studies on the seismic performance of shallow foundations are performed

62 mainly by the effective stress dynamic analyses, displacement-based sliding block analyses, or

63 force-based pseudo-static methods. In the pioneering studies, Meyerhof (1963) proposed a

64 convenient, simple method to evaluate the pseudo-static bearing capacity of shallow foundations,

65 in which equivalent constant seismic coefficients were applied at the centre of gravity of the

66 shallow foundation's failure zone. The method was extensively utilized in several subsequent

67 studies and in this way, many researchers tried to define a design procedure for shallow

68 foundations under pseudo-static loading condition (Sarma et al. 1990; Budhu and Al-Karni

69 1993; Richards et al. 1993; Dormieux and Pecker 1995; Paolucci and Pecker 1997; Soubra

70 1997, Kumar and Mohan Rao 2002; Choudhury and Subba Rao 2005; Cascone and

71 Casablanca 2016; Pane et al. 2016; Ghosh and Debnath 2017; Qin and Chian 2018; Conti

72 2018; Jamshidi Chenari et al. 2018; Cinicioglu and Erkli 2018; Izadi et al. 2019, 2021a;

73 Haghsheno et al. 2020; Zhang et al. 2020; Foroutan Kalourazi et al. 2021; Nouzari et al.

74 2021; Khazaei et al. 2021). Using the classical upper bound limit analysis method, Conti (2018)

75 developed the three-dimensional failure envelopes and derived formulations to evaluate the

76 seismic bearing capacity of eccentrically and obliquely loaded shallow foundations resting on the

77 cohesive-frictional and purely cohesive soils subjected to pseudo-static loading. 
78 Despite its great advantages, the so-called pseudo-static method fails to consider the concrete

79 dynamic nature of the seismic excitation, thus resulting in potentially unrealistic predictions of

80 the overall behaviour of the foundations and underlying soil layer subjected to seismic loading.

81 In an attempt to overcome such shortcomings, Steedman and Zeng (1990) and Choudhury and

82 Nimbalkar (2005) developed the conventional pseudo-dynamic method (CPD), so as to

83 incorporate the effects of phase difference and time in seismic analyses. In this approach, the

84 earthquake excitation is simulated through the propagation of shear and primary waves adopting

85 non-constant inertia forces along horizontal and vertical directions, respectively. In order to take

86 into account, the spectral characteristics of site response, Bellezza (2014) proposed a modified

87 pseudo-dynamic approach (MPD) based on the visco-elastic constitutive behaviour of the soil

88 medium to present a more realistic response of geo-structures under the effect of seismic waves.

89 The advantages of MPD over pseudo-static and conventional pseudo-dynamic include: $i$ )

90 satisfying the traction-free boundary condition at the ground surface, $i i)$ assessing the effects of

91 soil dynamics parameters such as material damping and shear wave velocity, and iii) considering

92 the effect of the time duration of the earthquake, phase difference, and reasonable amplification

93 of seismic forces. The conventional/modified pseudo-dynamic approach has been well

94 implemented in the literature to explore the seismic bearing capacity of shallow foundations

95 (Ghosh 2008; Saha and Ghosh 2015; Zhou et al. 2016; Saha and Ghosh 2017; Kurup and

96 Kolathayar 2018; Rezai Soufi et al. 2021). Saha and Ghosh (2015) presented a comparative

97 study on the pseudo-dynamic vertical bearing capacity of shallow strip footing using limit

98 equilibrium and limit analysis methods by considering the Coulomb failure mechanism. In

99 another study, Izadi et al. (2021b) deployed the limit equilibrium method to assess the influence

100 of the excitation frequency on the spectral seismic bearing capacity of shallow strip footings by 
101 invoking the conventional pseudo-dynamic approach. Recently, Safardoost Siahmazgi et al. 102 (2021) employed the lower bound limit analysis along with the finite element method to evaluate 103 the seismic vertical bearing capacity of a strip footing using conventional pseudo-dynamic 104 (CPD), spectral pseudo-dynamic (SPD), and modified pseudo-dynamic (MPD) approaches. 105 Krishnan and Chakraborty (2021) also explored the modified pseudo-dynamic bearing 106 capacity of strip footings over a horizontal ground of cohesionless soil using the lower bound 107 FELA method by generating the random field and spatial distribution of soil internal friction 108 angle though the soil stratum. Very recently, Rezaie Soufi et al. (2021) presented a 109 comprehensive comparison between the conventional and modified pseudo-dynamic approaches 110 in bearing capacity estimations for shallow footings. They vividly pinpointed the advantages of 111 MPD approach over the CPD method in terms of the capability to incorporate site effects and 112 damping characteristics of the soil deposit underneath shallow footing.

113 Despite the great number of research studies on the vertical bearing capacity of shallow 114 foundations in both static and dynamic loading conditions, there exists the lack of a systematic 115 work on the seismic bearing capacity of footings subjected to combined loading, especially under 116 the action of pseudo-dynamic loading. Indeed, nearly all the previous studies have been 117 restricted to vertical bearing capacity whose applicability for the foundations subjected to 118 combined loading is questionable. To fill this gap in the literature, this paper aims at evaluating 119 the pseudo-dynamic seismic bearing capacity of shallow foundations resting on a homogenous 120 cohesionless granular soil layer subjected to combined loading by lower bound finite element 121 limit analysis (FELA) and second-order cone programming (SOCP). Accordingly, the influence 122 of various parameters, including seismic accelerations and damping ratio, on the spectral 123 responses as well as failure envelopes is meticulously examined and discussed. 


\section{METHOD OF ANALYSIS}

126 In this section, the detailed formulations of the finite element limit analysis (FELA), simulation

127 of the eccentric and inclined loadings applied on the foundation and its incorporation into the 128 FELA formulations, and also the simulation of the modified pseudo-dynamic seismic loading are 129 thoroughly described.

\subsection{FELA formulations}

\subsubsection{Theoretical Background}

132 The lower bound theorem of limit analysis evaluates the lower bound of statically admissible 133 stress field within the soil medium at the ultimate limiting state. Following the progressive 134 evolution of the classical limit analysis over the years, Lysmer (1970) and Anderheggen and 135 Knopfel (1972) were the first to incorporate the finite element method into the conventional 136 limit analysis theorems so as to introduce the finite element limit analysis (FELA). This new 137 method utilized the numerical procedure to rectify the difficulties associated with the manual 138 simulation of stress field in a stability problem, specifically in the cases of complex geometries 139 and complicated loading scenarios. In this regard, Sloan (1988) introduced the general 140 formulations of lower bound FELA for the plane strain problems by means of linear 141 programming. The formulation deals mainly with the ultimate limit state of geo-structures and 142 thus, all the deformations occurring prior to failure and during collapse remain practically 143 insignificant. The corresponding FELA formulation was then used extensively in the literature 144 for the stability analysis of various geotechnical systems using either linear or nonlinear 145 programming (Basudhar et al. 1979; Sloan 1988; Lyamin and Sloan 2002a, b; Shiau et al. 146 2008; Veiskarami et al. 2017, 2019; Fathipour et al. 2020, 2021a, b, c; Mirmoazen et al. 147 2021; Izadi \& Jamshidi Chenari 2021a \& b). 


\subsubsection{Problem definition}

149 Fig. 1 shows the problem under study which consists of a shallow foundation resting on a 150 homogenous soil layer subjected to inclined and eccentric combined loading. The load $Q$ is 151 assumed to be applied with an inclination angle of $\alpha$ with respect to the vertical axis and at an 152 eccentric distance of $e$ from the footing centreline. The whole problem domain was extended 153 sufficiently so as to accommodate potential boundary effects. The soil beneath the foundation is 154 a cohesionless granular material, whose behaviour is considered to be elastic-perfectly plastic, 155 following the Mohr-Coulomb failure criterion with an associated flow rule $(\varphi=\psi)$. The internal 156 friction angle of the underlying soil are considered to be $\varphi=30^{\circ}$. The lower bound theorems of 157 limit analysis are implemented herein to provide a safe estimate of the ultimate combined 158 loading bearing capacity for a rigid shallow foundation overlying the corresponding granular 159 deposit.

\subsubsection{Fundamentals of finite element method}

161 As shown in Fig. 1, the whole soil medium underneath the shallow foundation has been 162 discretized by the linear three-nodded triangular elements. The nodal normal and shear stresses 163 in this finite element mesh, namely $\sigma_{x}, \sigma_{y}$, and $\tau_{x y}$, can be calculated adopting the lower bound 164 theorems of limit analysis for the bearing capacity problem. The unknown stresses at the points 165 other than the nodes could be estimated from the nodal stresses, using proper isoparametric 166 shape functions and adopting the Cartesian coordinate system and the right-handed rule, as 167 follow:

$$
\sigma_{x}=\sum_{i=1}^{3} N_{i} \sigma_{x, i} ; \quad \sigma_{y}=\sum_{i=1}^{3} N_{i} \sigma_{y, i} ; \quad \tau_{x y}=\sum_{i=1}^{3} N_{i} \tau_{x y, i}
$$


168 In these equations, the linear shape function is characterized by $N_{i}=\left(\xi_{i}+\eta_{i} x+\zeta_{i} y\right) / 2 A^{e}$, where

$169 \xi, \eta$ and $\zeta$ are shape function coefficients and $A^{e}$ is an area of each triangular element. The shape

170 function coefficients are defined based on the horizontal and vertical coordinates, as follow:

$$
\begin{aligned}
& \xi_{1}=x_{2} y_{3}-x_{3} y_{2} ; \quad \eta_{1}=y_{2}-y_{3} ; \quad \zeta_{1}=x_{3}-x_{2} \\
& \xi_{2}=x_{3} y_{1}-x_{1} y_{3} ; \quad \eta_{2}=y_{3}-y_{1} ; \quad \zeta_{2}=x_{1}-x_{3} \\
& \xi_{3}=x_{1} y_{2}-x_{2} y_{1} ; \quad \eta_{3}=y_{1}-y_{2} ; \quad \zeta_{3}=x_{2}-x_{1}
\end{aligned}
$$

171 The area of each triangular element in the finite element mesh is also estimated according to

$172 \quad A^{e}=\frac{1}{2}\left|\eta_{1} \zeta_{2}-\eta_{2} \zeta_{1}\right|$

173 According to the comprehensive study conducted by Sloan (1988), the finite element

174 formulations, as characterized above, could be incorporated into the lower bound theorems of

175 limit analysis. The resulting formulations of the finite element limit analysis for the assessment

176 of the bearing capacity of shallow foundations are summarized in the following sections. In this

177 framework, the matrix forms of different limit analysis constraints, including the element

178 equilibrium, the discontinuity equilibrium, the boundary conditions, and the yield criterion 179 enforcement are described and then assembled into the general optimization scheme.

\section{$180 \quad$ 2.1.4. Element equilibrium constraint}

181 According to the element equilibrium constraint, the triangular elements in the problem domain 182 and on the failure wedge must be in the equilibrium state due to all acting body forces. The 183 general equilibrium equations in the $x$ and $y$ directions are expressed as:

$$
\frac{\partial \sigma_{x}}{\partial x}+\frac{\partial \tau_{x y}}{\partial y}=\frac{a_{h}}{g} \gamma
$$




$$
\frac{\partial \sigma_{y}}{\partial y}+\frac{\partial \tau_{x y}}{\partial x}=\left(1+\frac{a_{v}}{g}\right) \gamma
$$

184 In the matrix notation, these equations can be presented as:

$$
\left[A_{\text {equil }}^{e}\right]\{\sigma\}=\left\{b_{\text {equil }}^{e}\right\}
$$

185 where

$$
\begin{aligned}
& {\left[A_{\text {equil }}^{e}\right]=\frac{1}{2 A^{e}}\left[\begin{array}{lll}
T_{1} & T_{2} & T_{3}
\end{array}\right], \quad T_{i}=\left[\begin{array}{ccc}
\eta_{i} & 0 & \zeta_{i} \\
0 & \zeta_{i} & \eta_{i}
\end{array}\right]} \\
& \{\sigma\}=\left\{\begin{array}{lllllllll}
\sigma_{x, 1} & \sigma_{y, 1} & \tau_{x y, 1} & \sigma_{x, 2} & \sigma_{y, 2} & \tau_{x y, 2} & \sigma_{x, 3} & \sigma_{y, 3} & \left.\tau_{x y, 3}\right\}^{T}
\end{array}\right. \\
& \left\{b_{\text {equil }}^{e}\right\}=\left\{\frac{a_{h}}{g} \gamma\left(1+\frac{a_{v}}{g}\right) \gamma\right\}^{T}
\end{aligned}
$$

\subsubsection{Discontinuity equilibrium constraint}

187 In the finite element limit analysis formulations, one single coordinate may be assigned to the 188 nodes of different elements. In other words, more than one node may share the same coordinate, 189 which means that the unknown stresses are generally discontinuous along adjacent edges of the 190 triangles. In order to satisfy the continuity of stresses throughout the problem domain, the normal 191 and shear nodal stresses on the permitted discontinuities are bound to be equal on the shared 192 planes at the common edges of the adjacent triangular elements; i.e. $\sigma_{n 1}=\sigma_{n 2}, \tau_{1}=\tau_{2}$; $193 \sigma_{n 3}=\sigma_{n 4}, \tau_{3}=\tau_{4}$ (Fig. 1). In the matrix notation, the constraint of discontinuity at each edge 194 of the triangular element could be described as in Eq. (4), based on the normal and shear stresses 195 acting on a plane having an angle $\alpha_{e}$ with respect to the $x$-axis; i.e. $\sigma_{n}=\sin ^{2} \alpha_{e}\left(\sigma_{x}\right)+$ $196 \cos ^{2} \alpha_{e}\left(\sigma_{y}\right)-\sin 2 \alpha_{e}\left(\tau_{x y}\right)$ and $\tau=-0.5 \sin 2 \alpha_{e}\left(\sigma_{x}\right)+0.5 \sin 2 \alpha_{e}\left(\sigma_{y}\right)+\cos 2 \alpha_{e}\left(\tau_{x y}\right)$

$$
\left[A_{\text {equil }}^{d}\right]\{\sigma\}=\left\{b_{\text {equil }}^{d}\right\}
$$

197 where 


$$
\begin{aligned}
& {\left[A_{\text {equil }}^{d}\right]=\left[\begin{array}{cccc}
T & -T & 0 & 0 \\
0 & 0 & T & -T
\end{array}\right], T=\left[\begin{array}{ccc}
\sin ^{2} \alpha_{e} & \cos ^{2} \alpha_{e} & -\sin 2 \alpha_{e} \\
-0.5 \sin 2 \alpha_{e} & 0.5 \sin 2 \alpha & \cos 2 \alpha_{e}
\end{array}\right]}
\end{aligned}
$$

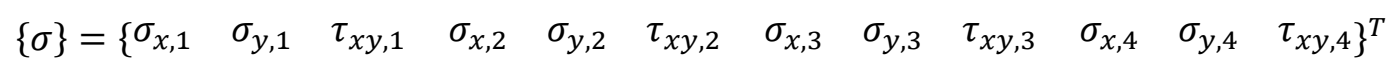

$$
\begin{aligned}
& \left\{b_{\text {equil }}^{d}\right\}=\left\{\begin{array}{llll}
0 & 0 & 0 & 0
\end{array}\right\}^{T}
\end{aligned}
$$

\section{$198 \quad$ 2.1.6. Boundary conditions}

199 The boundary conditions impose particular prescribed shear and normal stresses on the 200 boundaries of the problem domain, including the marginal surfaces and also the soil-structure 201 interfaces. In terms of the marginal surfaces, no external (overburden) loading is applied on the 202 ground surface, thus $\sigma_{n}=0$ and $\tau=0$ (Fig. 1). The matrix form of this constraint on the edges 203 of the horizontal ground surface can be expressed as follows:

$$
\left[A_{\text {bound }}^{g s}\right]\{\sigma\}=\left\{b_{\text {bound }}^{\text {gs }}\right\}
$$

204 where

$$
\begin{aligned}
& {\left[A_{\text {bound }}^{g s}\right]=\left[\begin{array}{ll}
T & 0 \\
0 & T
\end{array}\right], \quad T=\left[\begin{array}{lll}
0 & 1 & 0 \\
0 & 0 & 1
\end{array}\right]} \\
& \{\sigma\}=\left\{\begin{array}{llllll}
\sigma_{x, 1} & \sigma_{y, 1} & \tau_{x y, 1} & \sigma_{x, 2} & \sigma_{y, 2} & \tau_{x y, 2}
\end{array}\right\}^{T} \\
& \left\{b_{\text {bound }}^{g s}\right\}=\left\{\begin{array}{llll}
0 & 0 & 0 & 0
\end{array}\right\}^{T}
\end{aligned}
$$

205 In terms of boundary condition at the contact surface between the foundation and the underlying 206 soil deposit, the magnitude of the mobilized shear stress at the soil-foundation interface should 207 not exceed the shear strength of the interface, i.e. $\left|\tau_{x y}\right| \leq-\sigma_{y} \tan \delta$, where $\delta$ is the interface 208 friction angle. In the matrix form, this can be presented by the following inequality:

$$
\left[A_{\text {bound }}^{s-f}\right]\{\sigma\} \leq\left\{b_{\text {bound }}^{s-f}\right\}
$$

209 where 


$$
\begin{aligned}
& {\left[A_{\text {bound }}^{s-f}\right]=\left[\begin{array}{cc}
T & 0 \\
0 & T
\end{array}\right], \quad T=\left[\begin{array}{ccc}
0 & \tan \delta & -1 \\
0 & \tan \delta & 1
\end{array}\right]} \\
& \{\sigma\}=\left\{\begin{array}{llllll}
\sigma_{x, 1} & \sigma_{y, 1} & \tau_{x y, 1} & \sigma_{x, 2} & \sigma_{y, 2} & \tau_{x y, 2}
\end{array}\right\}^{T} \\
& \left\{b_{\text {bound }}^{s-f}\right\}=\left\{\begin{array}{llll}
0 & 0 & 0 & 0
\end{array}\right\}^{T}
\end{aligned}
$$

\subsubsection{Yield criterion enforcement}

211 As mentioned earlier, the soil mass beneath the shallow foundation in this study is considered to 212 be perfectly plastic, following the universal Mohr-Coulomb yield criterion. According to the

213 fundamental concepts of FELA approach, the mobilized stresses at all nodal points within the 214 soil medium should not exceed the Mohr-Coulomb yield function, defined as:

$$
F=\left(\sigma_{x}-\sigma_{y}\right)^{2}+\left(2 \tau_{x y}\right)^{2}-\left[-\left(\sigma_{x}+\sigma_{y}\right) \sin \varphi\right]^{2} \leq 0
$$

215 In this approach, in order to convert the Mohr-Coulomb yield function into the standard form of 216 the second-order cone programming, three nodal auxiliary variables are introduced as the

217 interrelationship between the nodal shear and normal stresses, as: $z_{1}=\left(\sigma_{x}-\sigma_{y}\right), z_{2}=2 \tau_{x y}$, 218 and $z_{3}=-\left(\sigma_{x}+\sigma_{y}\right) \sin \varphi$. The translation into the SOCP optimization scheme is conducted by 219 adopting the conic quadratic (second-order) constraint $\left(Q_{c}^{3}\right)$, defined as:

$$
Q_{c}^{3}=\left\{z \in R^{3}: \sqrt{z_{1, i}^{2}+z_{2, i}^{2}} \leq z_{3, i}\right\} \quad i=1,2,3, \ldots, \text { number } \text { of nodes }
$$

220 The matrix form of the corresponding interrelationship equation is expressed as:

$$
\left[A_{\text {yield }}\right]\{\sigma\}+I\{z\}=\left\{b_{\text {yield }}\right\}
$$

221 where 


$$
\begin{gathered}
{\left[A_{\text {yield }}\right]=\left[\begin{array}{ccc}
-1 & 1 & 0 \\
0 & 0 & -2 \\
\sin \varphi & \sin \varphi & 0
\end{array}\right]} \\
\{\sigma\}=\left\{\begin{array}{lll}
\sigma_{x} & \sigma_{y} & \tau_{x y}
\end{array}\right\}^{T} \\
\{z\}=\left\{\begin{array}{lll}
z_{1} & z_{2} & z_{3}
\end{array}\right\}^{T} \\
\left\{b_{\text {yield }}\right\}=\left\{\begin{array}{lll}
0 & 0 & 0
\end{array}\right\}^{T} \\
\text { I (identity matrix) }=\left[\begin{array}{lll}
1 & 0 & 0 \\
0 & 1 & 0 \\
0 & 0 & 1
\end{array}\right]
\end{gathered}
$$

222 The three nodal auxiliary variables, i.e. $z_{1}, z_{2}$ and $z_{3}$, are related to the nonlinear optimization 223 scheme adopted in the current study, which has been elaborated in the following section.

\section{$224 \quad$ 2.1.8. Simulation of eccentric and inclined combined loading}

225 In most practical cases, the shallow foundation supporting a superstructure is subjected to a 226 combination of vertical $(V)$, horizontal $(H)$ and moment $(M)$ loadings. It is therefore desirable to 227 find a yield envelope as a limiting surface of load combinations beyond which the foundation

228 would fail. The combined load $Q$ is defined by the vertical component $(V=Q \cos \alpha)$, the 229 horizontal component, $H=V \tan \alpha$, and an overturning moment, $M=V \times e$, where $\alpha$ and $e$ are 230 the inclination angle and load eccentricity, respectively. The force and moment equilibrium 231 equations are as follow:

$$
\begin{array}{ll}
\sum F_{x}=0: & Q \sin \alpha=\int_{S} \tau d x \\
\sum F_{y}=0: \quad Q \cos \alpha=\int_{S} \sigma_{n} d x \\
\sum M_{k z}=0: \quad \int_{S} x \sigma_{n} d x=0
\end{array}
$$


232 where $S$ is the foundation surface area, $x$ is the distance from the point of load application, $k$ is 233 the point of load application, and $\sigma_{n}$ and $\tau$ are the normal and shear stresses along the footing 234 nodes, respectively. Eqs. (10a) and (10b) could be divided and simplified into the following 235 correlation:

$$
\sin \alpha \int_{S} \sigma_{n} d x=\cos \alpha \int_{S} \tau d x
$$

236 In the matrix form, the equilibrium equations at each node along the soil-foundation interface are 237 expressed as follow:

$$
\begin{aligned}
& {\left[A_{\text {inc }}\right]\{\sigma\}=\left\{b_{\text {inc }}\right\}} \\
& {\left[A_{\text {ecc }}\right]\{\sigma\}=\left\{b_{\text {ecc }}\right\}}
\end{aligned}
$$

238 where

$$
\begin{aligned}
& {\left[A_{\text {inc }}\right]=[0, \sin \alpha,-\cos \alpha]} \\
& {\left[A_{e c c}\right]=[0, x, 0]} \\
& \{\sigma\}=\left\{\begin{array}{lll}
\sigma_{x} & \sigma_{y} & \tau_{x y}
\end{array}\right\}^{T} \\
& \left\{b_{\text {inc }}\right\}=\{0\} \\
& \left\{b_{e c c}\right\}=\{0\}
\end{aligned}
$$

239 Moreover, in order to allow segregation of the footing and underlying soil (which may occur due 240 to the developed tensile contact stress under eccentric loading condition), a "tension cut-off" 241 constraint must be applied to the soil-foundation interface nodes for the vertical normal stresses 242 beneath the foundation at each node being compressive (negative) only $\left(\sigma_{y} \leq 0\right)$ as:

$$
\left[A_{\text {bound }}^{\text {cut }}\right]\{\sigma\} \leq\left\{b_{\text {bound }}^{\text {cut }}\right\}
$$




$$
\begin{gathered}
{\left[A_{\text {equil }}^{\text {cut }}\right]=\left[\begin{array}{lll}
0 & 1 & 0
\end{array}\right]} \\
\{\sigma\}=\left\{\begin{array}{lll}
\sigma_{x} & \sigma_{y} & \tau_{x y}
\end{array}\right\}^{T} \\
\left\{b_{\text {bound }}^{\text {cut }}\right\}=\{0\}
\end{gathered}
$$

\subsubsection{Assembling \& Optimization}

244 In the preliminary formulation of FELA presented by Sloan (1988), the nonlinear form of Mohr-

245 Coulomb yield function (Eq. 7) was linearized and roughly approximated by interior regular

246 polygons of specific number of sides and vertices. With further evolution of optimization

247 programming in FELA concepts, several attempts were made to simulate the actual nonlinear

248 form of the corresponding yield criterion, with the seminal contributions of Lyamin and Sloan

249 (2002a, b), Makrodimopoulos and Martin (2005), and Krabbenhoft et al. (2008). Apart from

250 the superior precision of the obtained solutions, using such optimization can significantly

251 enhance the speed of computation. This issue is more pronounced for the evaluation of the

252 seismic bearing capacity of shallow foundations, which is intrinsically time-consuming because

253 of the high computational demand. The second-order cone programming (SOCP), as a nonlinear

254 optimization scheme, has been proven to be a quick, precise and the most appropriate technique

255 to evaluate the overall stability of various geo-structures (Makrodimopoulos and Martin 2006;

256 Fathipour et al. 2020, 2021a, b, c; Safardoost Siahmazgi et al. 2021, Izadi and Jamshidi

257 Chenari 2021a, b, among others). At the final stage, all the constraints are assembled into the

258 following general matrix form to obtain the unknown stress field using the second-order cone

259 optimization.

260 Following the general framework of the lower bound FELA, the objective function, which is the 261 vertical load bearing capacity of shallow footing defined as the integral of normal stresses $\left(\sigma_{n}\right)$ 262 along the soil-footing interface, must be maximized: 


$$
V=\operatorname{Maximize}\left\{-\int_{s} \sigma_{n} d x\right\}
$$

263 Subjected to

$$
\begin{gathered}
{[A]\{X\}=[B]} \\
\{X\}=\left\{\sigma ; z_{\text {socp }}\right\} \\
z_{\text {socp }} \in Q_{c}^{3}
\end{gathered}
$$

\section{2.2. Modified pseudo-dynamic seismic loading}

265 In the so-called pseudo-dynamic loading, a more realistic dynamic nature of the seismic 266 excitation is taken into account using various soil dynamic properties and spectral parameters of 267 the problem under study. In this way, a more viable response of the shallow foundation subjected 268 to seismic loading could be captured by simulating a visco-elastic material by means of the well269 defined Kelvin-Voigt model. The pseudo-dynamic method considers the influences of shear and 270 primary wave velocities, amplification of earthquake loading, and period of lateral shaking. It is

271 also assumed that the shear wave velocity and material damping are constant within the zone of 272 influence by shallow footing loading and the acceleration phase varies along the soil depth. In

273 the modified pseudo-dynamic approach, the earthquake accelerations with an angular frequency 274 of $\omega$ and a dominant period of $T$ (where $T=2 \pi / \omega$ ) are considered as a priori uniform 275 sinusoidal functions of time $(t)$ and depth $(y)$. The seismic horizontal and vertical accelerations 276 acting on the centroid of each element are in turn evaluated by the following modified pseudo277 dynamic functions so as to be representatives of the one-dimensional shear and primary waves, 278 respectively, propagating vertically through the soil mass from earthquake sources (Bellezza 279 2014). The horizontal and vertical earthquake acceleration components can be calculated as 280 follow: 


$$
\begin{aligned}
& a_{h}(y, t)=\frac{k_{h} g}{C_{S}^{2}+S_{S}^{2}}\left[\left(C_{S} C_{s y}+S_{S} S_{s y}\right) \cos \left(2 \pi \frac{t}{T}\right)+\left(S_{S} C_{s y}-C_{S} S_{s y}\right) \sin \left(2 \pi \frac{t}{T}\right)\right] \\
& a_{v}(y, t)=\frac{k_{v} g}{C_{P}^{2}+S_{P}^{2}}\left[\left(C_{P} C_{p y}+S_{P} S_{p y}\right) \cos \left(2 \pi \frac{t}{T}\right)+\left(S_{P} C_{p y}-C_{P} S_{p y}\right) \sin \left(2 \pi \frac{t}{T}\right)\right]
\end{aligned}
$$

281 where for the horizontal seismic acceleration, we have:

$$
\begin{gathered}
C_{S}=\cos \left(z_{S 1}\right) \cosh \left(z_{S 2}\right) \\
S_{S}=-\sin \left(z_{S 1}\right) \sinh \left(z_{S 2}\right) \\
C_{s y}=\cos \left(\frac{z_{S 1} y}{h}\right) \cosh \left(\frac{z_{S 2} y}{h}\right) \\
S_{s y}=-\sin \left(\frac{z_{S 1} y}{h}\right) \sinh \left(\frac{z_{S 2} y}{h}\right)
\end{gathered}
$$

282 where

$$
\begin{gathered}
z_{S 1}=\frac{2 \pi h}{T V_{s}} \sqrt{\frac{\sqrt{1+4 D^{2}}+1}{2\left(1+4 D^{2}\right)}} \\
z_{S 2}=-\frac{2 \pi h}{T V_{s}} \sqrt{\frac{\sqrt{1+4 D^{2}}-1}{2\left(1+4 D^{2}\right)}}
\end{gathered}
$$

283 In addition, for the vertical seismic acceleration, we have:

$$
\begin{gathered}
C_{P}=\cos \left(z_{p 1}\right) \cosh \left(z_{p 2}\right) \\
S_{P}=-\sin \left(z_{p 1}\right) \sinh \left(z_{p 2}\right) \\
C_{p y}=\cos \left(\frac{z_{p 1} y}{h}\right) \cosh \left(\frac{z_{p 2} y}{h}\right) \\
S_{p y}=-\sin \left(\frac{z_{p 1} y}{h}\right) \sinh \left(\frac{z_{p 2} y}{h}\right)
\end{gathered}
$$

284 where 


$$
\begin{gathered}
z_{p 1}=\frac{2 \pi h}{T V_{p}} \sqrt{\frac{\sqrt{1+4 D^{2}}+1}{2\left(1+4 D^{2}\right)}} \\
z_{p 2}=-\frac{2 \pi h}{T V_{p}} \sqrt{\frac{\sqrt{1+4 D^{2}}-1}{2\left(1+4 D^{2}\right)}}
\end{gathered}
$$

285 where $C_{s}, S_{S}, C_{S Z}, S_{S Z}, z_{s 1}, z_{s 2}$ are the coefficients of modified pseudo-dynamic horizontal 286 seismic acceleration; $C_{p}, S_{p}, C_{p z}, S_{p z}, z_{p 1}, z_{p 2}$ are the coefficients of modified pseudo-dynamic 287 vertical seismic acceleration; $k_{h}$ is the coefficient of horizontal acceleration at base (bedrock) 288 level; $k_{v}$ is the coefficient of vertical acceleration at base (bedrock) level; $g$ is the gravitational 289 acceleration; $t$ is the time of shaking; $y$ is the distance of element centroid from the ground 290 surface; $h$ is the thickness of the soil deposit beneath the footing; $V_{s}$ is the shear wave velocity; $291 V_{p}$ is the primary wave velocity, and $D$ is the material damping.

292 As an iterative algorithm, the MPD equations are incorporated into the FELA formulations. In 293 this regard, for any specific non-dimensional frequency $\left(h / T V_{s}\right)$, the bearing capacity is 294 evaluated and updated in each iteration for different values of shaking time $(t)$ in incremental 295 steps of $\Delta t / T=0.015$. The minimum value of bearing capacity during the shaking time is then 296 opted as the critical value for the vertical bearing capacity component $V$ optimized in Eq. (15) 297 for each time step. The other two loading components $(H$ and $M)$ are interchangeably calculated 298 from the optimized vertical loading component at critical shaking time. The joint contribution of 299 the horizontal and vertical earthquake acceleration coefficients is commonly considered in a 300 single parameter, namely the seismic angle defined as $\theta=\tan ^{-1}\left(k_{h} /\left(1-k_{v}\right)\right)$. Seismic angle 301 is characterized to represent the angle of deviation of the gravitational forces from the earth 302 gravitation force direction. Hence, $k_{h} /\left(1-k_{v}\right)$ represents the severity of earthquake loading 303 imposed on the soil medium and the overlying superstructure. In addition, in order to estimate 
304 the modified pseudo-dynamic seismic forces according to the practical assumptions reported by

305 Payan et al. (2017, 2020), $V_{p}$ is considered to be 1.87 times $V_{s}$ accounting for a typical constant

306 value of Poisson's ratio equal to 0.3 .

307 A step-by-step flowchart of the computational process of the modified pseudo-dynamic 308 formulations integrated with the finite element limit analysis theory is provided in Fig. 2 to have 309 a vision on the current study conducted methods.

\section{3. RESULTS \& DISCUSSION}

\section{3.1. Validation of FELA formulation for static combined bearing capacity}

313 In order to verify the accuracy of the current lower bound finite element limit analysis

314 formulations, the failure envelopes of shallow foundations under either inclined or eccentric

315 combined loading in static loading condition reported in the literature have been compared with

316 those obtained in the course of this study using the well-established FELA approach elaborated

317 in the previous section. The selected studies from the literature are the main ones in this area

318 which have utilized various theoretical and experimental approaches and also different numerical

319 methods such as finite element (FE), finite difference (FD), limit equilibrium (LE), FELA, etc.

320 Fig. 3a refers to the studies on obliquely-loaded footings, while Fig. 3b represents such a 321 comparison for the foundations under eccentric loading. Both types of envelopes have been 322 presented in a normalized fashion, as highly accepted in the literature. It should be noted that the 323 soil underlying shallow foundation in all these studies was cohesionless sand with an internal 324 friction angle of $35^{\circ}$. As it can be observed in the figures, the failure envelopes obtained with the 325 current FELA formulation are in great agreement with those reported in the literature for both 326 types of inclined and eccentric loading, as the envelopes in both cases approximately lie on the 
327 majority of the ones presented in the previous studies. With this superior capability, the FELA

328 formulations adopted in the current study are deemed sufficiently accurate in the prediction of 329 the bearing capacity of shallow foundations subjected to inclined and eccentric combined 330 loading. excitation

333 In this section, a comprehensive analysis has been carried out on the modified pseudo-dynamic 334 bearing capacity of obliquely-loaded shallow foundations. First, the spectral responses of 335 footings and the influences of seismic intensity and material damping ratio are examined. Then, 336 the failure envelopes of obliquely-loaded foundations subjected to modified pseudo-dynamic 337 excitation are presented in terms of various non-dimensional frequencies, seismic intensities and 338 material damping ratios.

\section{$339 \quad$ 3.2.1. Spectral responses}

\section{3.2.1.1. Influence of seismic intensity $\left(k_{h} /\left(1-k_{v}\right)\right)$}

341 Fig. 4 shows the spectral variations of normalized horizontal $\left(H / V_{\max (s t a t i c)}\right)$ and vertical

$342\left(V / V_{\max (\text { static })}\right)$ bearing capacity with respect to the non-dimensional frequency $\left(h / T V_{s}\right)$ for

343 obliquely-loaded shallow foundations subjected to modified pseudo-dynamic loading of various

344 seismic intensities $\left(k_{h} /\left(1-k_{v}\right)\right)$ with a constant typical material damping of 0.05 . It should be

345 noted that the values of the ultimate vertical and horizontal loads have been normalized with 346 respect to the maximum vertical load which could be sustained by the foundation in the static 347 loading condition. The figures in each row contain information related to a particular seismic 348 intensity. For each constant value of the seismic intensity $(0.1,0.15$ and 0.2$)$, the external load is 
349 considered to be applied on the footing at various inclination angles $(\alpha)$ ranging from $0^{\circ}$ to $30^{\circ}$ 350 by $6^{\circ}$ increments.

351 As highlighted in most pseudo-dynamic studies in the literature, in all cases, the spectral 352 normalized horizontal and vertical bearing capacities start with the pseudo-static loading 353 condition at very low frequencies (high wavelength) and end at very high frequencies (low 354 wavelengths). The corresponding two extremes of infinitely large and infinitesimal wavelengths 355 are associated with the uniform acceleration field in the pseudo-static condition and successively 356 counteracted inertia forces, respectively. In non-dimensional wavelengths between the two 357 extremes, the soil layer and the overlying foundation experience the so-called pseudo-dynamic 358 excitation, where the bearing capacity values could be observed to be more critical in most cases, 359 specifically in the resonance condition. To be more specific, in most non-dimensional 360 wavelengths in the spectral curves, the bearing capacity of shallow foundations could be 361 observed to be much lower than the corresponding values in the pseudo-static loading condition. 362 Hence, seismic analysis of foundations based on pseudo-static loading condition would most 363 probably lead to insecure and non-conservative designs. These deficiencies associated with the 364 pseudo-static approach arise predominantly from failing to consider the real seismic nature of 365 earthquake loading.

366 As it can be observed, the first mode of resonance occurs at the non-dimensional frequency of 367 approximately 0.25 for all cases irrespective of the input seismic acceleration and load 368 inclination. This is in full conformity to the theoretical estimations for the fundamental frequency 369 of a uniform, damped soil deposit on a rigid rock. In other words, the $n^{\text {th }}$ natural frequency of 370 such a layer would be $\omega_{n} \approx \frac{V_{s}}{h}\left(\frac{\pi}{2}+n \pi\right)$, where $n$ is the mode number ranging from $0,1,2, \ldots, \infty$; $371 V_{s}$ is the shear wave velocity of the soil layer, $h$ is the soil deposit thickness, and $\omega_{n}$ is the $n^{\text {th }}$ 
372 natural angular frequency of the layer (Kramer 1996). Deploying the above mentioned

373 relationship, the modal non-dimensional frequencies would be $h / T V_{s}=1 / 4+n / 2$, which

374 clearly explain why the first and second resonant non-dimensional frequencies in this study are

375 lying around 0.25 and 0.75 . In addition, at a given load inclination, as the seismic intensity

376 increases, more fluctuations in the spectral bearing capacity could be observed and in particular,

377 the extremum values of horizontal and vertical bearing capacity measures in the resonance state

378 are more affected. With the increase in the seismic intensity, the horizontal and vertical bearing

379 capacities expectedly decrease in value in a wide range of non-dimensional frequency. This is

380 more visible in the resonance condition where the ultimate bearing capacities take some

381 minimum values at relatively low seismic intensity ( 0.1 herein), whereas they are nearly zero for

382 the seismic intensities of 0.15 and 0.2 . Influence of seismic intensity on vertical and horizontal

383 bearing capacities is however further pronounced at the second mode of resonance (i.e., at $h$ /

$384 T V_{s}=0.75$ ), where the bearing capacity measures are much greater at lower seismic intensities. In

385 other words, as the seismic intensity increases, the changes in the normalized bearing capacities

386 are greater in the second mode of resonance as compared to the first mode.

387 At a given seismic intensity, as the load inclination increases, the variation of the normalized

388 vertical bearing capacity with the normalized frequency could be observed to become smoother

389 and at relatively high $\alpha$ values, say $30^{\circ}$, the wavelength has practically trivial or no influence on

390 the vertical bearing capacity. More interestingly, the bearing capacity values corresponding to

391 the static and pseudo-static loadings converge at noticeably high values of $\alpha$. Moreover, with the

392 increase in the load inclination, the ultimate vertical bearing capacity decreases with a fairly

393 constant rate for all seismic intensities and non-dimensional frequencies (Figs. 4a, 4c, 4e).

394 Despite the vertical bearing capacity, the ultimate horizontal load the foundation can sustain 
395 without reaching the failure state does not follow a constant increasing or decreasing trend.

396 Conversely, for all intensities of the incident wave, the horizontal bearing capacity and its 397 corresponding fluctuation increase with the load inclination up to about $12^{\circ}$, beyond which they 398 show reduction (Figs. $\mathbf{4 b}, \mathbf{4 d}, \mathbf{4 f})$. This observation can be attributed to the very fact that the 399 horizontal limit load component is coupled with its vertical counterpart, which undergoes sharp 400 reductions with load inclination. In other words, the horizontal limit load will be a multiplication 401 of two increasing $(\tan \alpha)$ and decreasing $(V)$ functions. After a certain load inclination, the 402 notable decline in the vertical limit load component would give rise the horizontal limit load to 403 start decreasing. Indeed, at the two extreme values of load inclinations under study, i.e. $0^{\circ}$ and $40430^{\circ}$, the variation of the normalized horizontal bearing capacity against non-dimensional 405 frequency becomes almost trivial. According to the above discussion, the approximate angle of $40612^{\circ}$ can be considered as the optimum load inclination rendering the most horizontal bearing 407 capacity. This value is a ballpark estimate and may be slightly different as all inclination angles 408 have not been shown in this figure. The more accurate optimum value can be captured from the 409 failure envelopes discussed in the following sections. Considering the spectral responses 410 presented in Fig. 4, it can be generally inferred that the foundation fails to function efficiently

411 when the load is applied with an inclination more than $30^{\circ}$. This threshold is equal to the adopted

412 internal/interface friction angle, which lends support to the contention that the critical load 413 inclination angle would be the interface friction angle, governed by the Coulomb law for 414 frictional materials.

\section{3.2.1.2. Influence of material damping (D)}

416 Fig. 5 shows the influence of material damping $(D)$ on the spectral variations of normalized 417 horizontal $\left(H / V_{\max (\text { static })}\right)$ and vertical $\left(V / V_{\max (\text { static })}\right)$ bearing capacities against the non- 
418 dimensional frequency $\left(h / T V_{s}\right)$ for obliquely-loaded shallow foundations subjected to modified

419 pseudo-dynamic loading with a constant typical seismic intensity of 0.2. Different values of 0.05,

$420 \quad 0.1$ and 0.2 have been considered for the material damping of the underlying sand layer in each

421 row of this figure. Once again, the first mode of resonance could be observed to occur at the non-

422 dimensional frequency of approximately 0.25 for all cases with no particular influence from the

423 load inclination and material damping. At a constant load inclination, as the material damping

424 increases, less fluctuation in the spectral bearing capacity as well as higher values of horizontal

425 and vertical bearing capacities could be captured. This observation is especially more

426 pronounced at non-dimensional frequencies higher than 0.5 near the second mode of resonance.

427 The phenomenon could be attributed primarily to the dissipation of incident waves due to the

428 high material damping of the underlying soil which in effect would diminish most of the seismic

429 energy emanated from the earthquake source, thus rendering greater values of vertical and

430 horizontal bearing capacities. For high values of material damping ( 0.2 herein) and at all load

431 inclination angles, non-dimensional frequency barely affects the spectral responses beyond

$432 h / T V_{s}=0.5$. As in the case highlighted for the effect of seismic intensity, the influence of material

433 damping on the spectral bearing capacity measures is more pronounced in the second mode of

434 resonance as compared to the first mode. Comparing Figs. 4 and 5, it can be generally observed

435 that at the first mode of resonance (i.e., $h / T V_{s}=0.25$ ), the seismic intensity has a greater impact

436 on the responses compared to the material damping. On the other hand, at the second mode of

437 resonance (i.e., $h / T V_{s}=0.75$ ), the material damping can be seen to have a higher influence on

438 both vertical and horizontal bearing capacities as compared to the seismic intensity.

439 Similar observations described earlier on the effect of load inclination on the spectral responses

440 of both vertical and horizontal bearing capacities could also be observed herein for various 
441 material damping ratios. Similarly, $12^{\circ}$ could be captured to be the optimum load inclination

442 angle offering the maximum horizontal bearing capacity for all material damping values. As

443 stated, this value is approximate and the more exact optimum inclination angle can be

444 distinguished from the failure envelopes discussed in the following sections.

\section{$445 \quad 3.2 .2$. Failure envelopes}

\section{$446 \quad 3.2 .2 .1$. Influence of non-dimensional frequency $\left(\mathrm{h} / \mathrm{TV} \mathrm{V}_{\mathrm{s}}\right)$}

447 Fig. 6 demonstrates the failure envelopes of obliquely-loaded shallow foundations subjected to 448 different non-dimensional frequencies $\left(h / T V_{s}\right)$ under a wide range of load inclinations from zero 449 to $36^{\circ}$. The seismic intensity and damping ratio have been considered to be constant and equal to 450 the typical values of 0.2 and 0.05 , respectively. From the full spectral curves presented earlier, 451 typical $h / T V_{s}$ values of extremely low (about zero corresponding to the pseudo-static condition), $4520.4,0.7,0.85$, and extremely high (infinity corresponding to the static condition) have been 453 selected for the illustration of the failure loci. As shown in Fig. 6a, the normalized vertical 454 bearing capacity decreases continuously with the inclination angle for all non-dimensional 455 frequencies. In addition, Fig. 6b shows that the normalized horizontal bearing capacity for all $456 h / T V_{s}$ values initially increases with the load inclination angle up to about $12^{\circ}$ to $14^{\circ}$, where it 457 shows reduction thereafter. As elaborated earlier, the horizontal limit load starts diminishing 458 after a certain stage due to the drastically reduced vertical limit load component. The inclination 459 angle at which the maximum $H / V_{\max (s t a t i c)}$ occurs is barely influenced by non-dimensional 460 frequency. This is due primarily to the fact that both the horizontal and vertical limit load 461 components are equally affected by the excitation frequency and their ratio remains almost 462 unaffected by the non-dimensional frequency. Close examination of Figs. $6 \mathbf{a}$ and $\mathbf{6 b}$ reveals that 463 the influence of non-dimensional frequency on the vertical and horizontal bearing capacities of 
464 surface footing under various modified pseudo-dynamic loading scenarios becomes fairly

465 negligible beyond the load inclination angle of about $30^{\circ}$, as all curves converge afterwards.

466 As shown in Fig. 6c, the general shapes of the yield surfaces in the normalized $V-H$ plane are

467 well described by a parabolic form, as also observed in several previous studies (Loukidis et al.

468 2008; Krabbenhoft et al. 2012; Zheng et al. 2019; among others). In all failure envelopes,

$469 \mathrm{H} / V_{\max (s t a t i c)}$ first increases with $V / V_{\max (\text { static) }}$ until it reaches a maximum value. With further

470 increase of $V / V_{\max (\text { static) }}$, the horizontal bearing capacity decreases up to where it reaches zero

471 (corresponding to $\alpha=0$ ) on the $V / V_{\max (s t a t i c)}$ axis. As it can be observed, the smallest failure

472 envelope among the ones presented herein is related to $h / T V_{s}=0.7$. It should be noted that the

473 smallest failure envelope among all non-dimensional frequencies, constituting literally zero

474 resistance of the strip footing against oblique loading in most cases, is related to the first mode of

475 resonance condition, where $h / T V_{s}=0.25$ (see Figs. 4 and 5). The values of $V / V_{\max (s t a t i c)}$ on the

476 horizontal axis at zero $H / V_{\max (s t a t i c)}$ for different curves shown in Fig. 6c also show that the

477 vertical bearing capacity is smaller for the non-dimensional frequency of 0.7 . In addition, the

478 value of $V / V_{\max (\text { static) }}$ where the maximum horizontal bearing capacity of the envelopes occurs

479 is lower for the case of $h / T V_{s}=0.7$. On the other hand, the largest failure envelope is not

480 unexpectedly pertaining to the static loading condition (high frequency/low wavelength) in

481 which the maximum horizontal bearing capacity occurs at the relatively higher $V / V_{\max }$ (static)

482 value compared to the other loading scenarios. As depicted in the spectral responses of the

483 surface footing in the previous section, with the increase in non-dimensional frequency, the

484 failure envelope becomes either larger or smaller in size depending on the adopted $h / T V_{s}$.

485 However, as mentioned above, it is evident that the worst case scenario belongs to the 
corresponding resonance condition where the minimum values of vertical and horizontal bearing

487 capacities are acquired.

\subsubsection{Influence of seismic intensity $\left(\boldsymbol{k}_{h} /\left(1-\boldsymbol{k}_{v}\right)\right)$}

489 Fig. 7 shows the significant influence of seismic intensity $\left(k_{h} /\left(1-k_{v}\right)\right)$ on the failure envelope 490 of obliquely-loaded shallow foundations subjected to a wide range of load inclinations. In these 491 envelopes, the material damping is assumed to be constant and equal to 0.05 and the soil mass is 492 considered to be subjected to the modified pseudo-dynamic loading at the typical non493 dimensional frequencies of 0.4 and 0.7. As illustrated in Figs. 7a, 7b, 7d and 7e, as the load 494 inclination increases, $V / V_{\max (s t a t i c)}$ decreases while the $H / V_{\max (s t a t i c)}$ first increases and then 495 decreases past the peak value which occurs at the inclination angles of approximately $12^{\circ}$ to $14^{\circ}$; 496 the angle which is not affected by the seismic intensity. Figs. 7c and 7f show that the failure 497 envelope markedly shrinks as the seismic intensity increases from 0.1 to 0.2 . The reduction in the 498 size of failure envelopes is more pronounced in the case of $h / T V_{s}=0.7$, where the size of failure 499 envelope decreases significantly to almost its half size with the increase in the seismic angle 500 from 0.1 to 0.2 . It should be emphasized that the two non-dimensional frequencies examined 501 here are typical values and the contribution of the seismic intensity to the amount of reduction of 502 the size of failure envelopes directly depends on the non-dimensional frequency of the 503 earthquake excitation (see Figs. 4 and 5). In addition, with the increase of seismic intensity, $504 \mathrm{~V} / V_{\max (\text { static) }}$ at which the maximum normalized horizontal bearing capacity occurs, shifts to 505 lower values, which is more pronounced in the case of $h / T V_{s}=0.7$. The values of $V / V_{\max }$ (static) 506 when $H / V_{\max (\text { static })}=0$ demonstrate that the vertical bearing capacity of the foundation 507 decreases when it is subjected to higher seismic intensities. 
508 The effect of seismic intensity is more pronounced at the lower inclination angles and turns out 509 to be insignificant after a specific $\alpha$ value of about $27^{\circ}$ to $30^{\circ}$. This observation can be ascribed

510 to the very fact that at high load inclination angles, both the vertical and horizontal limit load 511 components are low and the footing failure is governed by the footing-soil interface failure.

512 Indeed, due to the very low vertical limit load values, the horizontal limit load is governed by the

513 footing sliding at the interface level. This idea has been substantiated by illustrating some sample

514 failure patterns for different load inclination values, as shown in Fig. 8. As shown in this figure,

515 at a given seismic intensity in the static and pseudo-static conditions, as the inclination angle

516 increases from $0^{\circ}$ to $20^{\circ}$, the failure zone decreases in size. In other words, the size of passive

517 zone in the side of load inclination significantly decreases compared to the other side, thus

518 revealing a reduction in the overall bearing capacity of the foundation. In addition, in the case of

519 vertical loading (zero load inclination angle), the passive failure zone at the side of pseudo-static

520 load application gradually diminishes as the seismic intensity increases from 0 to 0.2 . However,

521 as the inclination angle increases, the diminished passive wedge reappears and has the most

522 impact on resisting the oblique load. Moreover, with the increase in the inclination angle, the

523 influence of seismic intensity on the failure zones notably decreases. This phenomenon is more

524 pronounced at relatively high inclination angles (say $20^{\circ}$ herein), as the failure zones for different

525 seismic intensities are almost similar. It is worth mentioning that in the cases assumed in Fig. 8,

526 the load inclination and the pseudo-static load are applied in the opposite directions. This

527 explains why they have counteracting influence on the failure mechanism underneath the

528 footing. However, the most critical condition will manifestly occur when they are in the same 529 direction. 
531 Fig. 9 shows the influence of material damping $(D)$ on the failure envelope of obliquely-loaded

532 shallow foundations subjected to a wide range of load inclinations. The seismic intensity is

533 assumed to be constant and equal to 0.2 and the soil mass is considered to be subjected to the

534 modified pseudo-dynamic loading at the typical non-dimensional frequencies of 0.4 and 0.7 . As

535 depicted in Figs. 9a, 9b, 9d and $9 e$, the trends of variations of $V / V_{\max (\text { static) }}$ and $H / V_{\max (\text { static) }}$

536 with inclination angle are quite similar to the previous cases. Once again, the maximum

537 horizontal limit loads for different damping ratios occur at an inclination angle of $12^{\circ}$ to $14^{\circ}$.

538 According to the Figs. 9c and 9f, with the increase in the material damping from 0.05 to 0.2 , the

539 failure envelope in the normalized $V-H$ plane expands, thereby bearing witness to the greater

540 resistance of the obliquely-loaded footing against seismic loading. The contribution of damping

541 ratio to the increase in the size of failure envelope is more pronounced at the non-dimensional

542 frequency of 0.7. Indeed, when $h / T V_{s}=0.4$, material damping could be observed to have no

543 significant influence on the failure envelope. Once again, it should be highlighted that the two

$544 h / T V_{s}$ values examined here are only two typical values and the contribution of material

545 damping to the amount of increase in the size of failure envelopes directly depends on the non-

546 dimensional frequency induced by the earthquake excitation (see Figs. 4 and 5).

547 The contribution of damping ratio to the augmentation of the bearing capacity is also less

548 pronounced at higher inclination angles. To be more specific, beyond a particular inclination

549 angle of approximately $27^{\circ}$, the damping ratio barely affects the failure envelopes. As explained

550 earlier, by increasing the load inclination angle, due to the shallow failure condition as acquired

551 from Fig. 8, the site amplification properties pale to insignificance. Furthermore, the $V /$

$552 V_{\max (\text { static) }}$ values corresponding to the maximum horizontal bearing capacity increase with the

553 increase in the damping ratio. 

excitation

556 The modified pseudo-dynamic bearing capacity of eccentrically-loaded shallow foundations has

557 been examined in this section. Similar to the previous section, first, the influences of seismic 558 acceleration and material damping on the spectral responses of surface footings are discussed. In 559 the second part, the failure loci of eccentrically-loaded shallow foundations under the action of 560 modified pseudo-dynamic excitation are presented accounting for the effects of non-dimensional 561 frequency, seismic intensity and damping ratio.

\subsubsection{Spectral responses}

563 3.3.1.1. Influence of seismic intensity $\left(\boldsymbol{k}_{h} /\left(1-\boldsymbol{k}_{v}\right)\right)$

564 The influence of seismic intensity on the spectral variations of normalized moment $(M /$ $\left.565 B V_{\max (\text { static) }}\right)$ and vertical $\left(V / V_{\max (\text { static })}\right)$ bearing capacity of eccentrically-loaded shallow 566 foundations is illustrated in Fig. 10. The eccentricity ratio $(e / B)$ in each seismic intensity has 567 been considered to vary from 0 to 0.4 . Once again, the spectral normalized vertical and moment 568 bearing capacities in all cases start with the pseudo-static loading condition at very low 569 frequencies and end at the static loading condition at very high frequencies. The bearing capacity 570 values associated with the static and pseudo-static loadings converge at considerably high values 571 of load eccentricity.

572 As it can be observed and similar to the case of inclined loading, irrespective of the values of the 573 input seismic acceleration and load eccentricity, the first mode resonance occurs at the non574 dimensional frequency of approximately 0.25 for all cases. At a constant load eccentricity, with 575 the increase in the seismic intensity, more fluctuations and relatively smaller spectral vertical and 576 moment bearing capacities could be captured; the trend which is more pronounced in the first 
577 and second modes of resonance state especially at smaller seismic intensities. Indeed, the bearing

578 capacities are practically zero at the first and second modes of resonance at high seismic

579 intensity and thus, the foundation has no resistance against the applied external loading.

580 Furthermore, the effect of seismic intensity on vertical and moment bearing capacities is more

581 pronounced at the second mode of resonance, occurring at approximately $h / T V_{s}=0.75$, as the

582 changes in the bearing capacities due to the increase of the seismic intensity in the corresponding

583 mode of resonance is much greater compared to the first mode.

584 At a given seismic intensity, with the increase in the load eccentricity, the ultimate vertical

585 bearing capacity decreases in a fairly constant rate and the spectral variations of $V / V_{\max (\text { static })}$

586 could be observed to become smoother and at relatively high eccentricity ratios $(e / B$ values of

587 approximately 0.4 ), the non-dimensional frequency has no significant influence on the vertical

588 bearing capacity (Figs. 10a, 10c, 10e). On the contrary, at a constant seismic intensity, the

589 normalized moment bearing capacity and its corresponding fluctuations increase with the load

590 eccentricity ratio up to about $e / B$ ratio of 0.2 (to be determined more precisely in the failure

591 envelopes), and decrease thereafter (Figs. 10b, 10d, 10f). Likewise the inclination effect, the

592 developed moment bearing capacity is a synergy of both the eccentricity and the vertical limit

593 load per se; indeed, after a certain eccentricity ratio, let's say 0.2 , the vertical limit load decreases

594 substantially, thus, rendering an overall decreasing moment bearing capacity. As a result, it can

595 be generally expressed that the surface footing fails to function efficiently when the load is 596 applied with an eccentricity of more than about $0.4 B$.

\section{$597 \quad$ 3.3.1.2. Influence of material damping (D)}

598 The influence of material damping on the spectral variations of normalized moment $(M /$ $\left.599 B V_{\max (\text { static) }}\right)$ and vertical $\left(V / V_{\max (\text { static) }}\right)$ bearing capacity of eccentrically-loaded surface 
600 footings is depicted in Fig. 11. Similarly, it can be observed that the first mode of resonance

601 condition occurs at the non-dimensional frequency of approximately 0.25 for all cases

602 irrespective of the material damping and load eccentricity. Considering a given load eccentricity,

603 the increase in the material damping gives rise to the significant reduction of the fluctuations as

604 well as noticeable increase in the vertical and moment bearing capacities, particularly after

$605 h / T V_{s}=0.5$. In other words, for high values of material damping and at all load eccentricities,

606 non-dimensional frequency bears no particular effect on the vertical and moment bearing

607 capacities of the shallow foundation when subjected to the earthquake excitation with $h / T V_{s}$

608 values of more than 0.5. As in the case of the effect of seismic intensity, the influence of material

609 damping on the spectral bearing capacity turns out to be more pronounced in the second mode of

610 resonance as compared to the first mode. With a comparison between Figs. 10 and 11, it can be

611 generally concluded that at the first mode of resonance (i.e., $h / T V_{s}=0.25$ ), the seismic intensity

612 has a greater influence on the spectral responses as compared to the material damping. At the

613 second mode of resonance (i.e., $h / T V_{s}=0.75$ ), in turn, the material damping can be observed to

614 more substantially affect the bearing capacities compared to the seismic intensity.

\section{$615 \quad 3.3 .2$. Failure envelopes}

\section{3.3.2.1. Influence of non-dimensional frequency $\left(\boldsymbol{h} / \mathbf{T} \boldsymbol{V}_{s}\right)$}

617 Fig. 12 shows the failure envelopes of eccentrically-loaded surface footings under different load

618 eccentricity ratios ranging from 0 to 0.5 and subjected to various non-dimensional frequencies of

6190 (the pseudo-static condition), 0.4, 0.7, 0.85 and 1 (the static condition). As shown in Figs. 12a

620 and $\mathbf{1 2 b}$ and similar to the cases for the inclined loading, the normalized vertical bearing capacity

621 decreases continuously with the load eccentricity for all non-dimensional frequencies, whereas

622 the normalized moment bearing capacity first increases with the eccentricity ratio up to about 
$6231 / 6$, and reduces thereafter. The load eccentricity where the maximum moment bearing capacity

624 occurs is not affected by non-dimensional frequency. The influence of non-dimensional

625 frequency on the vertical and moment bearing capacities turns out to be insignificant beyond the

626 load eccentricity ratio of about 0.4. As shown in Fig. 12c, the smallest failure envelope, among

627 the ones examined herein, associated with the minimum resistance of eccentrically-loaded

628 shallow foundation is related to the non-dimensional frequency of 0.7. In addition, as discussed

629 for the spectral responses, as the non-dimensional frequency changes, the failure envelope

630 becomes either larger or smaller in size depending on the imposed non-dimensional frequency.

\section{$631 \quad$ 3.3.2.2. Influence of seismic intensity $\left(\boldsymbol{k}_{h} /\left(1-k_{v}\right)\right)$}

632 Fig. 13 illustrates the influence of seismic intensity on the failure envelope of eccentrically-

633 loaded shallow foundations subjected to the modified pseudo-dynamic loading at the typical non-

634 dimensional frequencies of 0.4 and 0.7. As observed, similar to the inclined loading, with the

635 increase in the seismic intensity from 0.1 to 0.2 , the failure envelope significantly shrinks, thus

636 highlighting the substantial influence of earthquake-induced accelerations on the moment

637 bearing capacity of strip footings. As it can be perceived from this figure, the influence of

638 seismic intensity on the failure envelopes is more remarkable at the lower load eccentricities and

639 is almost negligible beyond an eccentricity ratio of approximately 0.35 . This trend of variation

640 can be attributed to the very shallow and skewed failure mechanism when the eccentricity ratio

641 rises; hence, lending support to the contention that the shallow failure mechanisms are less

642 affected by the site effects. Moreover, with the increase of seismic intensity, the value of

$643 \mathrm{~V} / V_{\max (\text { static) }}$ corresponding to the maximum normalized moment bearing capacity decreases.

644 Fig. 14 illustrates the failure patterns of eccentrically-loaded shallow foundations under static 645 and pseudo-static loading conditions. As depicted, at a given seismic intensity, as the load 
646 eccentricity increases from 0 to $B / 3$, the failure zone significantly shrinks, thereby rendering a

647 noticeable reduction in the overall bearing capacity of the footing. Moreover, the failure wedges

648 shift horizontally with the load eccentricity so as to appear underneath the point of load

649 application. Furthermore, in the case of vertical concentric loading $(e / B=0)$, as the seismic

650 intensity increases from 0 to 0.2 , the passive failure zone at the side of pseudo-static load

651 application gradually diminishes. However, with the increase in the load eccentricity, the

652 corresponding passive wedge comes into sight again. The impact of seismic intensity on the sizes

653 and shapes of failure zones is almost similar for all load eccentricities. As stated earlier for the

654 impact of load inclination, the direction of the pseudo-static loading in Fig. $\mathbf{1 4}$ is to the contrary

655 of the load eccentricity. This means that their effects on the bearing capacity of the overlying

656 shallow footing would counteract each other. In other words, what is presented in Fig. 14 is not

657 the most critical case; however, it has been brought up to isolate the two different effects and to

658 better illustrate the way the failure mechanism is transforming underneath the footing due to the

659 application of the eccentric loading under the influence of horizontal pseudo-static loading

660 component.

\section{$661 \quad 3.3 .2 .3$. Influence of material damping $(D)$}

662 Fig. 15 shows the influence of material damping on the failure envelope of eccentrically-loaded 663 shallow foundations subjected to modified pseudo-dynamic loading at the typical non664 dimensional frequencies of 0.4 and 0.7. As depicted in Figs. 15a, 15b, 15d and 15e, the 665 maximum horizontal limit loads for different damping ratios occur at an approximate eccentricity 666 ratio of 1/6. This eccentricity ratio theoretically constitutes no tensile stress formation underneath 667 the footing. Based on the failure envelopes in the normalized $V-M$ plane shown in Figs. 15c 668 and 15f, the increase in the material damping from 0.05 to 0.2 yields the failure envelope 
expansion, indicating greater resistance of the eccentrically-loaded shallow foundation against

670 seismic loading. The contribution of damping ratio increase to the expansion of the failure

671 envelope, however, is directly influenced by the non-dimensional frequency imposed by the

672 earthquake excitation (see Figs. 10 and 11). Accordingly, at the non-dimensional frequency of

673 0.4, material damping has no particular influence on the failure envelope, while it has a sound

674 effect on the failure loci at $h / T V_{s}=0.7$.

675 As depicted in Figs. 15c and 15f, the failure envelope in the $V / V_{\max (\text { static) }}-M / B V_{\max (\text { static) }}$

676 plane expands as the material damping increases from 0.05 to 0.2 . It could also be observed that

677 the effect of damping ratio on the failure loci is more pronounced when the external load is

678 applied on the foundation with a lower eccentricity. In particular, after a specific eccentricity

679 ratio of approximately 0.35 to 0.4 , material damping pales to insignificance. Moreover, the

$680 \mathrm{~V} / V_{\max (\text { static) }}$ values associated with the maximum moment bearing capacity increase as the 681 damping ratio increases.

682

\section{4. CONCLUDING REMARKS}

684 In this study, the seismic bearing capacity of shallow strip foundation overlying a cohesionless 685 soil layer subjected to inclined and eccentric combined loading was examined through a 686 comprehensive set of lower bound finite element limit analyses (FELA) using the second-order 687 cone programming (SOCP). The actual nonlinear form of the rigid plastic Mohr-Coulomb yield 688 criterion, the equilibrium equations associated with the applied combined loading and also the 689 well-established modified pseudo-dynamic approach were all incorporated into the FELA 690 formulations. The adopted formulation was rigorously validated against a majority of high- 
691 quality studies in the literature for the static loading condition. From the results of numerical 692 simulations, the following results were drawn:

693 - The first mode of resonance occurs at the non-dimensional frequency of approximately $694 \quad 0.25$ for all cases, irrespective of the imposed seismic acceleration, material damping, 695 load inclination and load eccentricity. In addition, at a given inclination angle or load 696 eccentricity, as the seismic intensity increases, more fluctuations and relatively smaller 697 spectral vertical, horizontal and moment bearing capacities could be captured; the trend 698 which is more pronounced in the first and second modes of resonance state especially at $699 \quad$ smaller seismic intensities.

700 - At a given seismic intensity and material damping, as the inclination angle or load 701 eccentricity increases, the variation of the normalized vertical bearing capacity with the 702 non-dimensional frequency could be observed to become smoother. Moreover, with the 703 increase in $\alpha$ or $e$, the ultimate vertical bearing capacity decreases. Conversely, for all 704 intensities of incident waves, the horizontal or moment bearing capacity and their 705 corresponding fluctuations increase up to a particular value of inclination angle or load 706 eccentricity, respectively, beyond which they exhibit reduction.

$707 \quad-\quad$ The failure envelopes of the shallow foundation subjected to either inclined or eccentric 708 loading significantly shrink with the increase in the earthquake accelerations and 709 decrease in the material damping of the underlying soil mass. The amount of changes in 710 the size of failure envelopes in the normalized $V-H$ and $V-M$ spaces due to the 711 variation of seismic intensity and material damping depends directly on the non712 dimensional frequency of the earthquake excitation. 
- In most non-dimensional frequencies in the spectral curves, the bearing capacity of shallow foundations could be observed to be much lower than the corresponding values in the pseudo-static loading condition, especially in the resonance conditions where almost zero bearing capacities were captured in most of the cases studied. Hence, seismic analysis of foundations based on pseudo-static loading condition would most probably lead to insecure and non-conservative designs. These deficiencies associated with the pseudo-static approach arise predominantly from failing to consider the real seismic nature of earthquake loading. The modified pseudo-dynamic approach examined in this study considers a more realistic nature of earthquake shaking, thus it can be a better representative of the seismic loading applied on various geo-structures. Therefore, the bearing capacity measured using this approach and subsequent failure envelopes are more realistic.

\section{REFERENCES}

727 Anderheggen, E., \& Knöpfel, H. (1972). Finite element limit analysis using linear programming. 728 International Journal of Solids and Structures, 8(12), 1413-1431.

Basudhar, P. K., Valsangkar, A. J., \& Madhav, M. R. (1979). Optimal lower bound of passive earth pressure using finite elements and non-linear programming. International Journal for Numerical and Analytical Methods in Geomechanics, 3(4), 367-379.

733 Geological Engineering, 32(2), 561-576.

734 Bransby, M. F., \& Randolph, M. F. (1998). Combined loading of skirted foundations. Géotechnique, 735 48(5), 637-655.

736 Budhu, M., \& Al-Karni, A. (1993). Seismic bearing capacity of soils. Geotechnique, 43(1), 181-187.

737 Cascone, E., \& Casablanca, O. (2016). Static and seismic bearing capacity of shallow strip footings. Soil 738 Dynamics and Earthquake Engineering, 84, 204-223. 
739 Choudhury, D., \& Nimbalkar, S. (2005). Seismic passive resistance by pseudo-dynamic method.

740 Geotechnique, 55(9), 699-702.

741 Cinicioglu, O., \& Erkli, A. (2018). Seismic bearing capacity of surficial foundations on sloping cohesive

742 ground. Soil Dynamics and Earthquake Engineering, 111, 53-64.

743 Conti, R. (2018). Simplified formulas for the seismic bearing capacity of shallow strip foundations. Soil

744 Dynamics and Earthquake Engineering, 104, 64-74.

745 Dormieux, L., \& Pecker, A. (1995). Seismic bearing capacity of foundation on cohesionless soil. Journal 746 of Geotechnical Engineering, 121(3), 300-303.

747 Fathipour, H., Siahmazgi, A. S., Payan, M., \& Chenari, R. J. (2020). Evaluation of the lateral earth 748 pressure in unsaturated soils with finite element limit analysis using second-order cone programming. $749 \quad$ Computers and Geotechnics, 125, 103587.

750 Fathipour, H., Payan, M., Jamshidi Chenari, R., \& Senetakis, K. (2021a). Lower bound analysis of 751 modified pseudo-dynamic lateral earth pressures for retaining wall-backfill system with depth-varying damping using FEM-Second order cone programming. International Journal for Numerical and Analytical Methods in Geomechanics.

Fathipour, H., Siahmazgi, A. S., Payan, M., Veiskarami, M., \& Jamshidi Chenari, R. (2021b). Limit analysis of modified pseudodynamic lateral earth pressure in anisotropic frictional medium using finite-element and second-order cone programming. International Journal of Geomechanics, 21(2), 04020258 .

Fathipour, H., Payan, M., \& Chenari, R. J. (2021c). Limit analysis of lateral earth pressure on geosynthetic-reinforced retaining structures using finite element and second-order cone programming. Computers and Geotechnics, 134, 104119.

Foroutan Kalourazi, A., Izadi, A., \& Jamshidi Chenari, R. (2019). Seismic bearing capacity of shallow strip foundations in the vicinity of slopes using the lower bound finite element method. Soils and Foundations, 59(6), 1891-1905.

Ganesh, R., Khuntia, S., \& Sahoo, J. P. (2017). Bearing capacity of shallow strip foundations in sand under eccentric and oblique loads. International Journal of Geomechanics, 17(4), 06016028.

Ghosh, P. (2008). Upper bound solutions of bearing capacity of strip footing by pseudo-dynamic approach. Acta Geotechnica, 3(2), 115-123.

Ghosh, S., \& Debnath, L. (2017). Seismic bearing capacity of shallow strip footing with coulomb failure mechanism using limit equilibrium method. Geotechnical and Geological Engineering, 35(6), 2647 2661.

772 general planar loading. Géotechnique, 49(4), 453-469. 
773 Gourvenec, S. (2007). Shape effects on the capacity of rectangular footings under general loading.

774 Géotechnique, 57(8), 637-646.

775 Haghsheno, H., Jamshidi Chenari, R., Javankhoshdel, S., \& Banirostam, T. (2020). Seismic bearing 776 capacity of shallow strip footings on sand deposits with weak inter-layer. Geotechnical and Geological 777 Engineering, 38(6), 6741-6754.

778 Hansen, J. B. (1970). A revised and extended formula for bearing capacity.

779 Izadi, A., Nazemi Sabet Soumehsaraei, M., Jamshidi Chenari, R., \& Ghorbani, A. (2019). Pseudo-static bearing capacity of shallow foundations on heterogeneous marine deposits using limit equilibrium method. Marine Georesources \& Geotechnology, 37(10), 1163-1174.

Izadi, A., Foroutan Kalourazi, A., \& Jamshidi Chenari, R. (2021a). Effect of roughness on seismic bearing capacity of shallow foundations near slopes using the lower bound finite element method. International Journal of Geomechanics, 21(3), 06020043.

Izadi, A., Nazemi Sabet Soumehsaraei, M., Jamshidi Chenari, R., Moallemi, S., \& Javankhoshdel, S. (2021b). Spectral bearing capacity analysis of strip footings under pseudo-dynamic excitation. Geomechanics and Geoengineering, 16(5), 359-378.

Izadi, A., \& Jamshidi Chenari, R. (2021a). Three dimensional undrained bearing capacity analysis of laterally loaded pile in heterogeneous marine deposits. Marine Georesources \& Geotechnology, 1-23.

Izadi, A., and Jamshidi Chenari, R. (2021b). Three Dimensional Finite Element Lower Bound Solutions for Lateral Limit Load of Piles Embedded in Anisotropic Clay Deposits. International Journal of Geomechanics 10.1061/(ASCE)GM.1943-5622.0002208.

Jamshidi Chenari, R., \& Mahigir, A. (2014). The effect of spatial variability and anisotropy of soils on bearing capacity of shallow foundations. Civil Engineering Infrastructures Journal, 47(2), 199-213.

Jamshidi Chenari, R., Zhalehjoo, N., \& Karimian, A. (2014). Estimation on bearing capacity of shallow foundations in heterogeneous deposits using analytical and numerical methods. Scientia Iranica. Transaction A, Civil Engineering, 21(3), 505.

Jamshidi Chenari, R., \& Mahigir, A. (2017). The effect of mechanical anisotropy and heterogeneity of shear strength parameters of soils on drained bearing capacity of shallow foundations. Computational Methods in Engineering, 36(1), 137-147.

Jamshidi Chenari, R. J., Izadi, A., \& Somesaraie, M. N. (2018). Discussion of "seismic bearing capacity 803 of shallow strip footing with coulomb failure mechanism using limit equilibrium method" by S. Geological Engineering, 36(6), 4037-4040. 
Jamshidi Chenari, R., Izadi, A., Eslami, A., \& Khaksar Najafi, E. (2019). Approximation of undrained bearing capacity of strip foundations on heterogeneous marine clay. International Journal of Numerical Methods in Civil Engineering, 3(3), 20-27.

Keawsawasvong, S., Thongchom, C., \& Likitlersuang, S. (2021). Bearing capacity of strip footing on Hoek-Brown rock mass subjected to eccentric and inclined loading. Transportation Infrastructure Geotechnology, 8(2), 189-202.

Khazaei, A., Rezaie Soufi, G., \& Jamshidi Chenari, R. (2021). Lower-bound seismic bearing capacity of a strip footing adjacent to an existing footing on sand. International Journal of Geomechanics, 21(8), 04021128.

Krabbenhøft, K., Lyamin, A. V., \& Sloan, S. W. (2008). Three-dimensional Mohr-Coulomb limit analysis using semidefinite programming. Communications in Numerical Methods in Engineering, 24(11), 1107-1119.

Krabbenhoft, S., Damkilde, L., \& Krabbenhoft, K. (2012). Lower-bound calculations of the bearing capacity of eccentrically loaded footings in cohesionless soil. Canadian Geotechnical Journal, 49(3), 298-310.

Kramer, S. L. (1996). Geotechnical earthquake engineering. Prentice Hall, New Jersey.

Krishnan, K., \& Chakraborty, D. (2021). Seismic bearing capacity of strip footing over spatially random soil using modified pseudo-dynamic approach. Computers and Geotechnics, 136, 104219.

Kumar, J., \& Mohan Rao, V. B. K. (2002). Seismic bearing capacity factors for spread foundations. Geotechnique, 52(2), 79-88.

Kurup, S. S., \& Kolathayar, S. (2018). Seismic bearing capacity factor considering composite failure mechanism: pseudo-dynamic approach. International Journal of Geotechnical Earthquake Engineering (IJGEE), 9(1), 65-77.

Loukidis, D., Chakraborty, T. and Salgado, R., (2008). Bearing capacity of strip footings on purely frictional soil under eccentric and inclined loads. Canadian Geotechnical Journal, 45(6), pp.768-787.

Lyamin, A. V., \& Sloan, S. W. (2002a). Lower bound limit analysis using non-linear programming. International Journal for Numerical Methods in Engineering, 55(5), 573-611.

Lyamin, A. V., \& Sloan, S. W. (2002b). Upper bound limit analysis using linear finite elements and nonlinear programming. International Journal for Numerical and Analytical Methods in Geomechanics, 26(2), 181-216.

Mirmoazen, S. M., Lajevardi, S. H., Mirhosseini, S. M., Payan, M., \& Jamshidi Chenari, R. (2021). Active lateral earth pressure of geosynthetic-reinforced retaining walls with inherently anisotropic frictional backfills subjected to strip footing loading. Computers and Geotechnics, 137, 104302. 
Meyerhof, G. G. (1963). Some recent research on the bearing capacity of foundations. Canadian Geotechnical Journal, 1(1), 16-26.

Nouzari, M. A., Jamshidi Chenari, R., Payan, M., \& Pishgar, F. (2021). Pseudo-static seismic bearing capacity of shallow foundations in unsaturated soils employing limit equilibrium method. Geotechnical and Geological Engineering, 39(2), 943-956.

Nova, R., \& Montrasio, L. (1991). Settlements of shallow foundations on sand. Géotechnique, 41(2), 243256.

Okamura, M., Mihara, A., Takemura, J., \& Kuwano, J. (2002). Effects of footing size and aspect ratio on the bearing capacity of sand subjected to eccentric loading. Soils and Foundations, 42(4), 43-56.

Ouahab, M. Y., Mabrouki, A., Frank, R., Mellas, M., \& Benmeddour, D. (2020). Undrained bearing capacity of strip footings under inclined load on non-homogeneous clay underlain by a rough rigid base. Geotechnical and Geological Engineering, 38(2), 1733-1745.

Pane, V., Vecchietti, A., \& Cecconi, M. (2016). A numerical study on the seismic bearing capacity of shallow foundations. Bulletin of Earthquake Engineering, 14(11), 2931-2958.

Paolucci, R., \& Pecker, A. (1997). Seismic bearing capacity of shallow strip foundations on dry soils. Soils and Foundations, 37(3), 95-105.

Pakdel, P., Jamshidi Chenari, R., \& Veiskarami, M. (2019). An estimate of the bearing capacity of shallow foundations on anisotropic soil by limit equilibrium and soft computing technique. Geomechanics and Geoengineering, 14(3), 202-217.

Pakdel, P., Jamshidi Chenari, R., \& Veiskarami, M. (2021). Seismic bearing capacity of shallow foundations rested on anisotropic deposits. International Journal of Geotechnical Engineering, 15(2), 181-192.

Payan, M., Senetakis, K., Khoshghalb, A., \& Khalili, N. (2017). Effect of gradation and particle shape on small-strain Young's modulus and Poisson's ratio of sands. International Journal of Geomechanics, 17(5), 04016120.

Payan, M., Khoshini, M., \& Jamshidi Chenari, R. (2020). Elastic dynamic Young's modulus and Poisson's ratio of sand-silt mixtures. Journal of Materials in Civil Engineering, 32(1), 04019314.

Pham, Q. N., Ohtsuka, S., Isobe, K., \& Fukumoto, Y. (2020). Limit load space of rigid footing under eccentrically inclined load. Soils and Foundations, 60(4), 811-824.a

Pham, Q. N., Ohtsuka, S., Isobe, K., Fukumoto, Y., \& Hoshina, T. (2019). Ultimate bearing capacity of rigid footing under eccentric vertical load. Soils and Foundations, 59(6), 1980-1991.

Prakash, S., \& Saran, S. (1971). Bearing capacity of eccentrically loaded footings. Journal of the Soil Mechanics and Foundations Division, 97(1), 95-117. 
871 Purkayastha, R. D., \& Char, R. A. (1977). Stability analysis for eccentrically loaded footings. Journal of 872 the Geotechnical Engineering Division, 103(6), 647-651.

873 Qin, C., \& Chian, S. C. (2018). Seismic bearing capacity of non-uniform soil slopes using discretization874 based kinematic analysis considering Rayleigh waves. Soil Dynamics and Earthquake 875 Engineering, 109, 23-32.

876 Ranjbar Pouya, K., Zhalehjoo, N., \& Jamshidi Chenari, R. (2014). Influence of random heterogeneity of 877 cross-correlated strength parameters on bearing capacity of shallow foundations. Indian Geotechnical 878 Journal, 44(4), 427-435.

879 Rezaie Soufi, G., Jamshidi Chenari, R., and Javankhoshdel, S. (2021). Conventional vs. modified pseudo880 dynamic seismic analyses in bearing capacity problem. Earthquake Engineering and Engineering Vibration (in press).

Richards Jr, R., Elms, D. G., \& Budhu, M. (1993). Seismic bearing capacity and settlements of 883 foundations. Journal of Geotechnical Engineering, 119(4), 662-674.

Safardoost Siahmazgi, A., Fathipour, H., Jamshidi Chenari, R., Veiskarami, M., \& Payan, M. (2021). Evaluation of the pseudo-dynamic bearing capacity of surface footings on cohesionless soils using finite element lower bound limit analysis. Geomechanics and Geoengineering, 1-13.

Saha, A., \& Ghosh, S. (2015). Pseudo-dynamic analysis for bearing capacity of foundation resting on c- $\Phi$ soil. International Journal of Geotechnical Engineering, 9(4), 379-387.

Saha, A., \& Ghosh, S. (2017). Modified pseudo-dynamic bearing capacity analysis of shallow strip footing considering total seismic wave. International Journal of Geotechnical Engineering.

Saran, S., \& Agarwal, R. K. (1991). Bearing capacity of eccentrically obliquely loaded footing. Journal of Geotechnical Engineering, 117(11), 1669-1690.

Saran, S., Prakash, S., \& Murty, A. V. S. R. (1971). Bearing capacity of footings under inclined loads. Soils and Foundations, 11(1), 47-52.

Sargazi, O., \& Hosseininia, E. S. (2017). Bearing capacity of ring footings on cohesionless soil under eccentric load. Computers and Geotechnics, 92, 169-178.

Sarma, S. K., \& Iossifelis, I. S. (1990). Seismic bearing capacity factors of shallow strip footings. Geotechnique, 40(2), 265-273.

Shiau, J. S., Augarde, C. E., Lyamin, A. V., \& Sloan, S. W. (2008). Finite element limit analysis of passive earth resistance in cohesionless soils. Soils and Foundations, 48(6), 843-850.

901 Sloan, S. W. (1988). Lower bound limit analysis using finite elements and linear programming. 902 International Journal for Numerical and Analytical Methods in Geomechanics, 12(1), 61-77. 
Soubra, A. H., \& COULOMB. (1997). Seismic bearing capacity of shallow strip footings in seismic conditions. Proceedings of the Institution of Civil Engineers-Geotechnical Engineering, 125(4), 230241.

Steedman, R. S., \& Zeng, X. (1990). The influence of phase on the calculation of pseudo-static earth pressure on a retaining wall. Geotechnique, 40(1), 103-112.

Taiebat, H. A., \& Carter, J. P. (2002). Bearing capacity of strip and circular foundations on undrained clay subjected to eccentric loads. Geotechnique, 52(1), 61-64.

Tsuchida, T., \& Athapaththu, A. M. R. G. (2014). Practical slip circle method of slices for calculation of bearing capacity factors. Soils and Foundations, 54(6), 1127-1144.

Ukritchon, B., Whittle, A. J., \& Klangvijit, C. (2003). Calculations of bearing capacity factor N $\gamma$ using numerical limit analyses. Journal of Geotechnical and Geoenvironmental Engineering, 129(5), 468474.

Veiskarami, M., Jamshidi Chenari, R., \& Jameei, A. A. (2017). Bearing capacity of strip footings on anisotropic soils by the finite elements and linear programming. International Journal of Geomechanics, 17(12), 04017119.

Veiskarami, M., Jamshidi Chenari, R., \& Jameei, A. A. (2019). A study on the static and seismic earth pressure problems in anisotropic granular media. Geotechnical and Geological Engineering, 37(3), 1987-2005.

Vesic AS (1973) Analysis of ultimate loads of shallow foundations. J Soil Mech Found Div ASCE 99(1):45-73

Yahia-Cherif, H., Mabrouki, A., Benmeddour, D., \& Mellas, M. (2017). Bearing capacity of embedded strip footings on cohesionless soil under vertical and horizontal loads. Geotechnical and Geological Engineering, 35(2), 547-558.

Yun, G., \& Bransby, M. F. (2007). The horizontal-moment capacity of embedded foundations in undrained soil. Canadian Geotechnical Journal, 44(4), 409-424.

Zhang, R., Xiao, Y., Zhao, M., \& Jiang, J. (2020). Seismic bearing capacity of strip footings placed near c- $\varphi$ soil slopes. Soil Dynamics and Earthquake Engineering, 136, 106221.

Zheng, G., Zhao, J., Zhou, H., \& Zhang, T. (2019). Ultimate bearing capacity of strip footings on sand overlying clay under inclined loading. Computers and Geotechnics, 106, 266-273. 


\section{FIGURES}

938

939

940

941

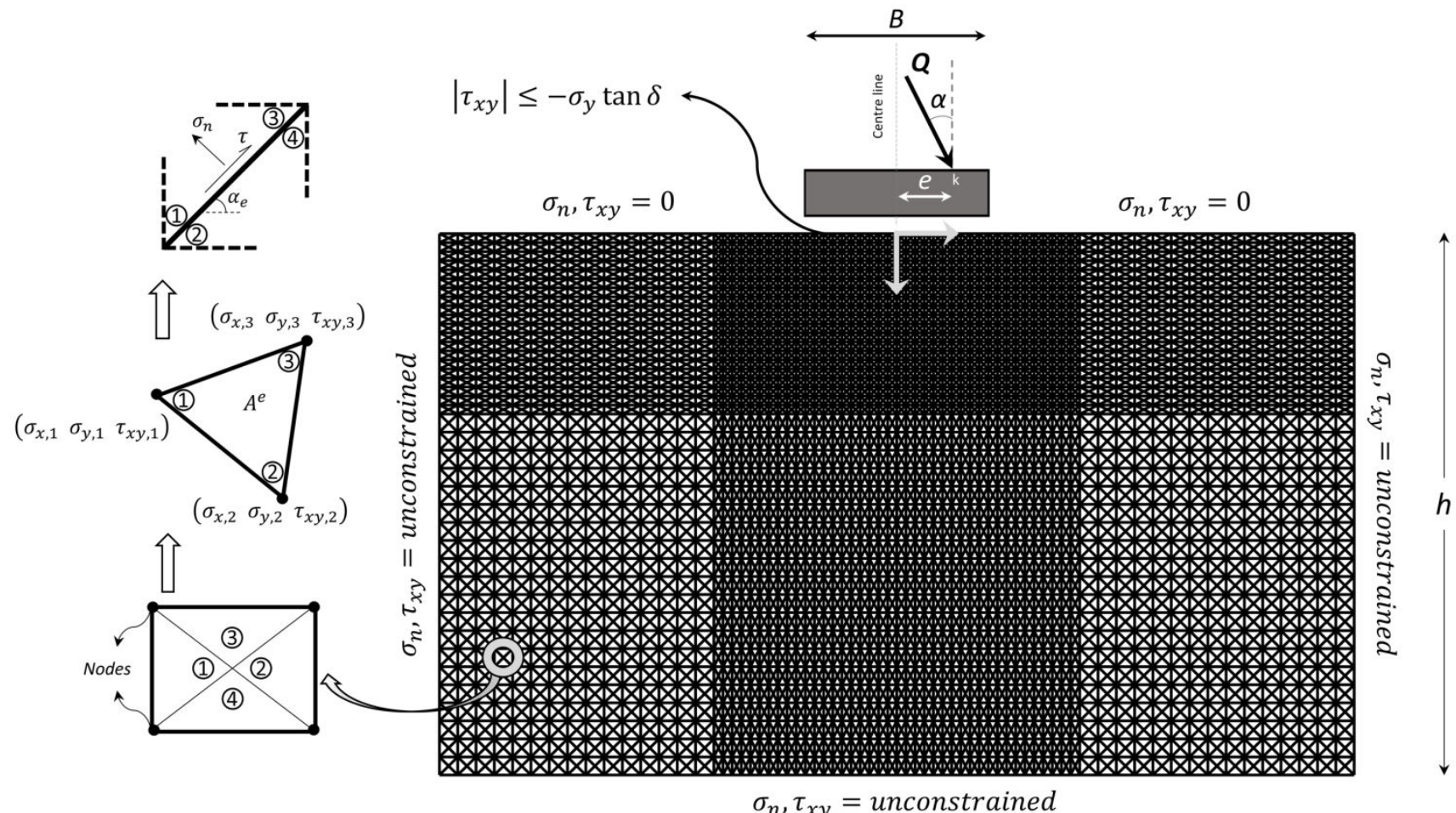

Fig 1. Triangular discretization of the soil medium beneath the shallow foundation subjected to inclinedeccentric combined loading 


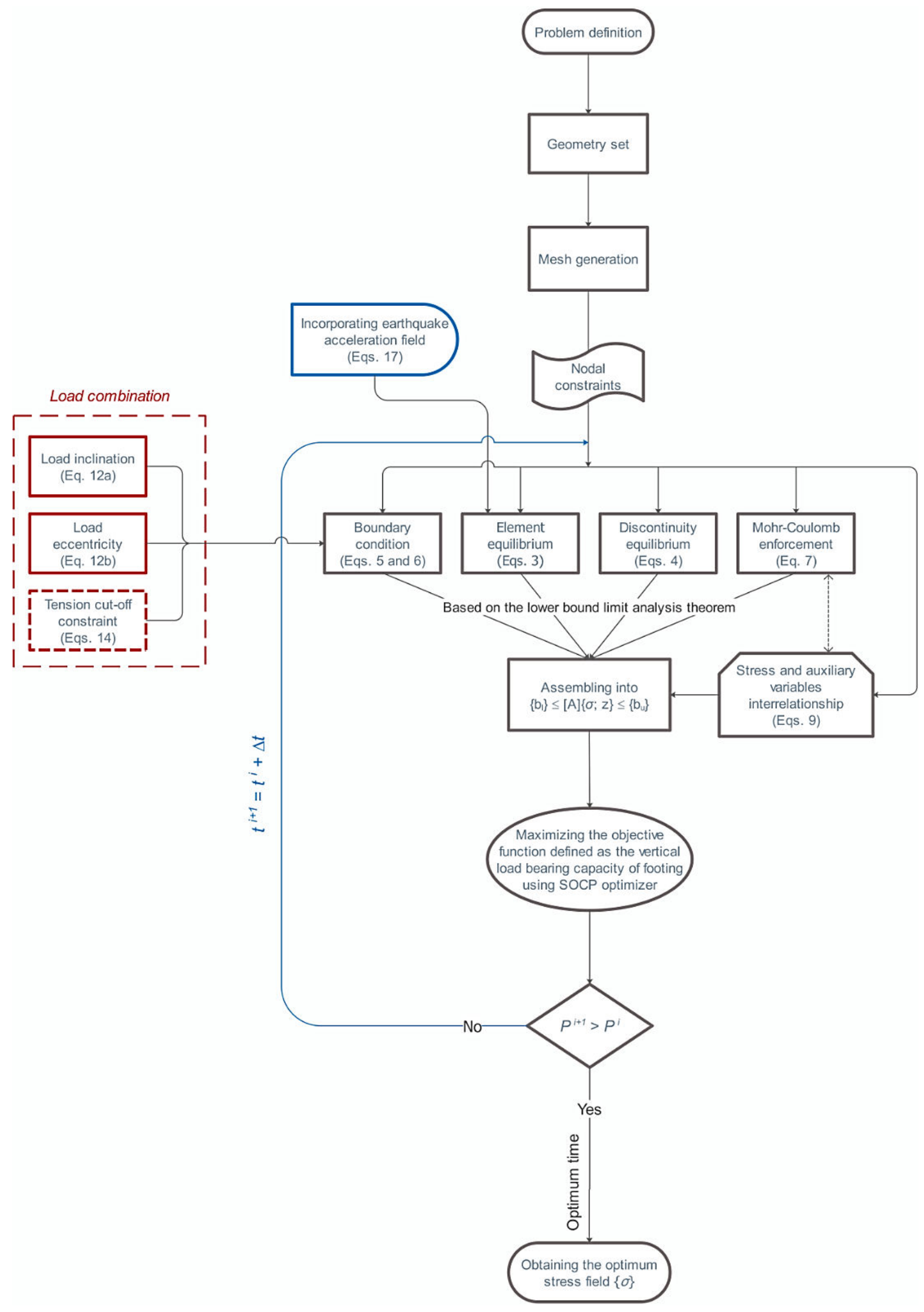

Fig 2. Flowchart of the detailed computational procedure followed for the estimation of the modified pseudo-dynamic bearing capacity of shallow foundation subjected to inclined-eccentric combined loading 

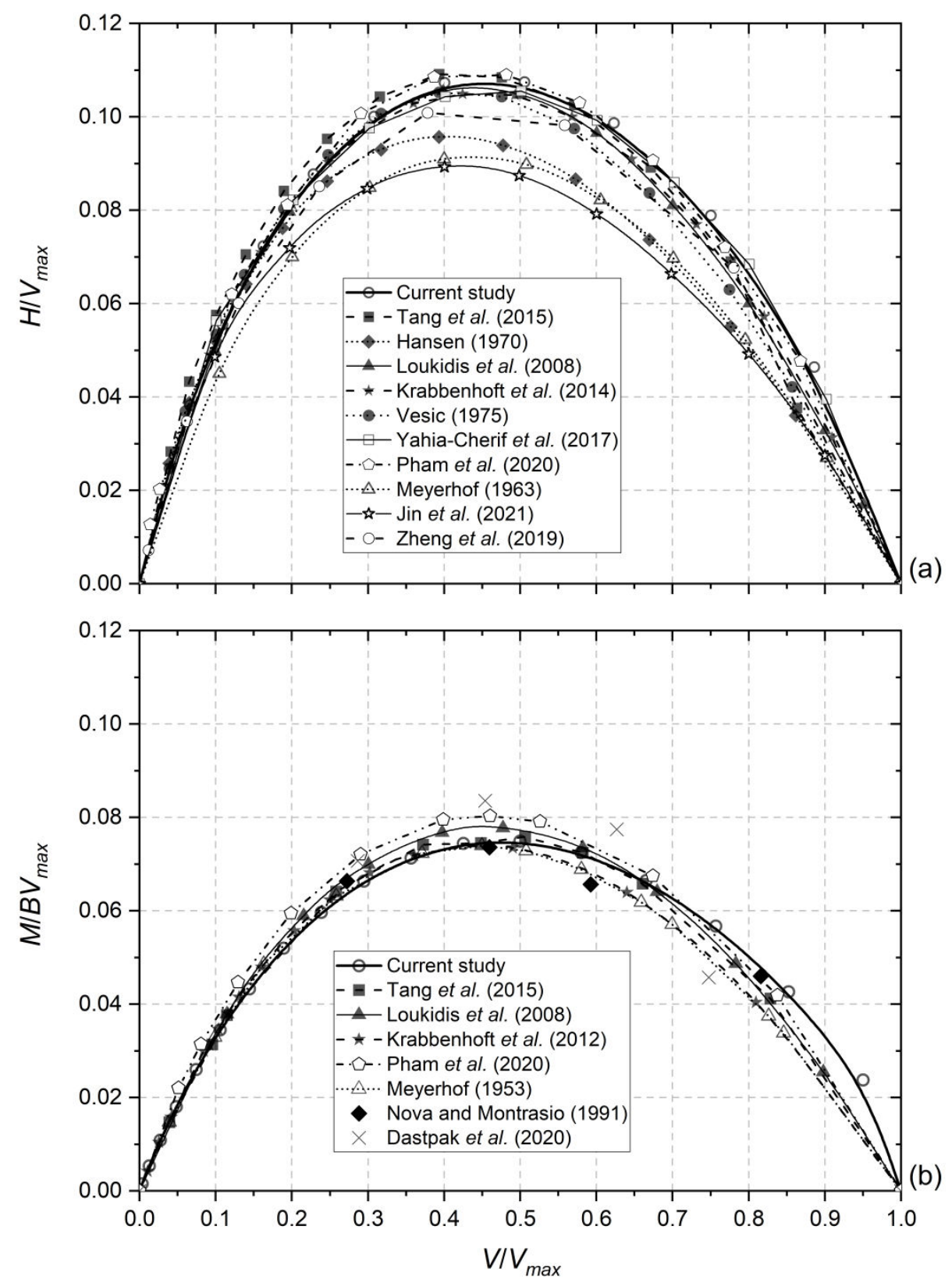

952 Fig 3. Comparison of the failure envelopes between the results of the FELA simulations conducted in the current study and those reported in the previous studies using various theoretical/experimental/numerical 

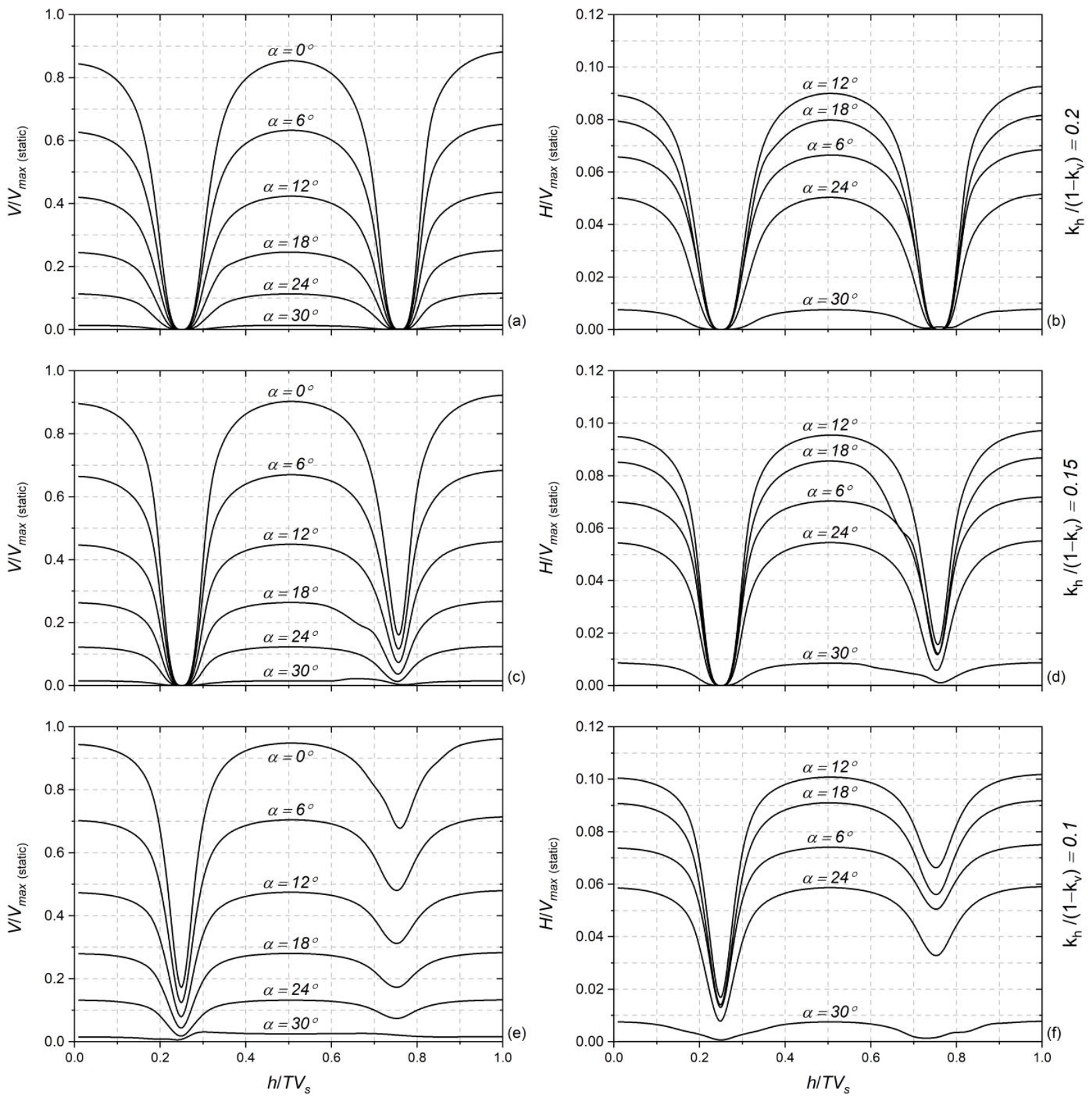

Fig. 4. Influence of seismic intensity $\left(k_{h} /\left(1-k_{v}\right)\right)$ on the spectral modified pseudo-dynamic bearing capacity of obliquely-loaded shallow foundations subjected to a wide range of load inclinations $(D=0.05)$ 

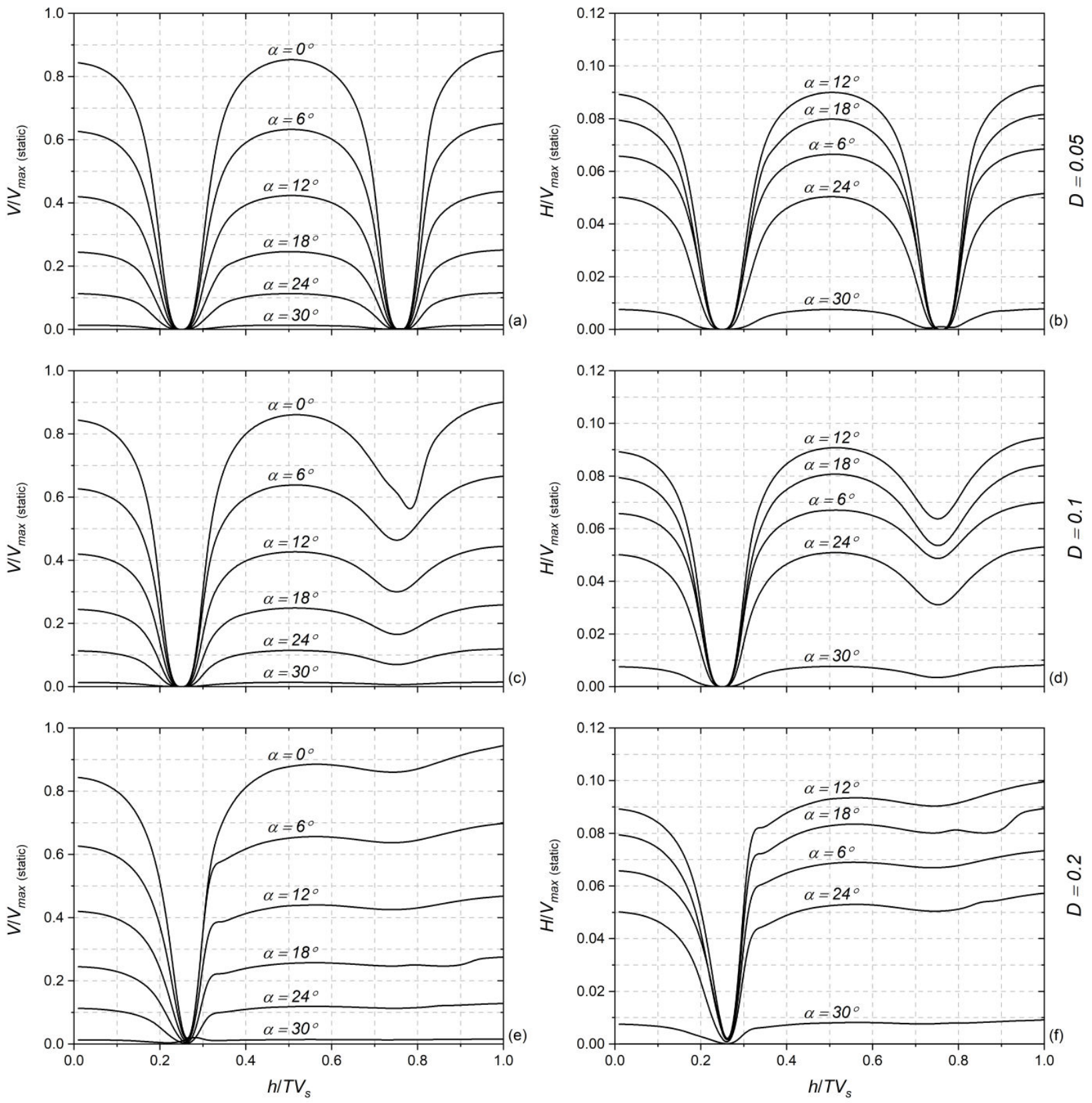

Fig. 5. Influence of material damping $(D)$ on the modified pseudo-dynamic bearing capacity of obliquelyloaded shallow foundations subjected to a wide range of load inclinations $\left(k_{h} /\left(1-k_{v}\right)=0.2\right)$ 

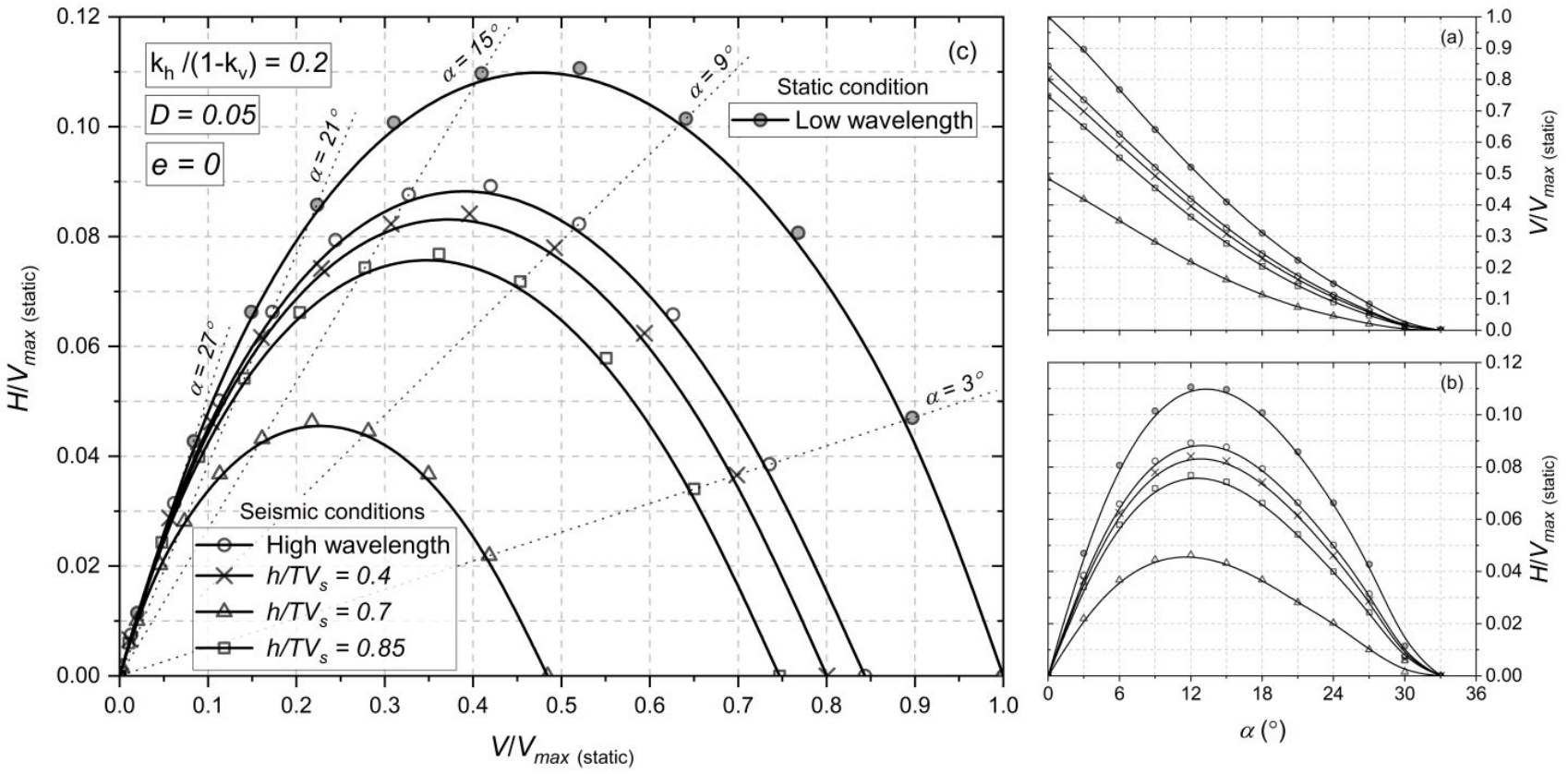

Fig. 6. Failure envelopes of obliquely-loaded shallow foundations subjected to various non-dimensional frequencies under a wide range of load inclinations $\left(k_{h} /\left(1-k_{v}\right)=0.2, D=0.05\right)$ 

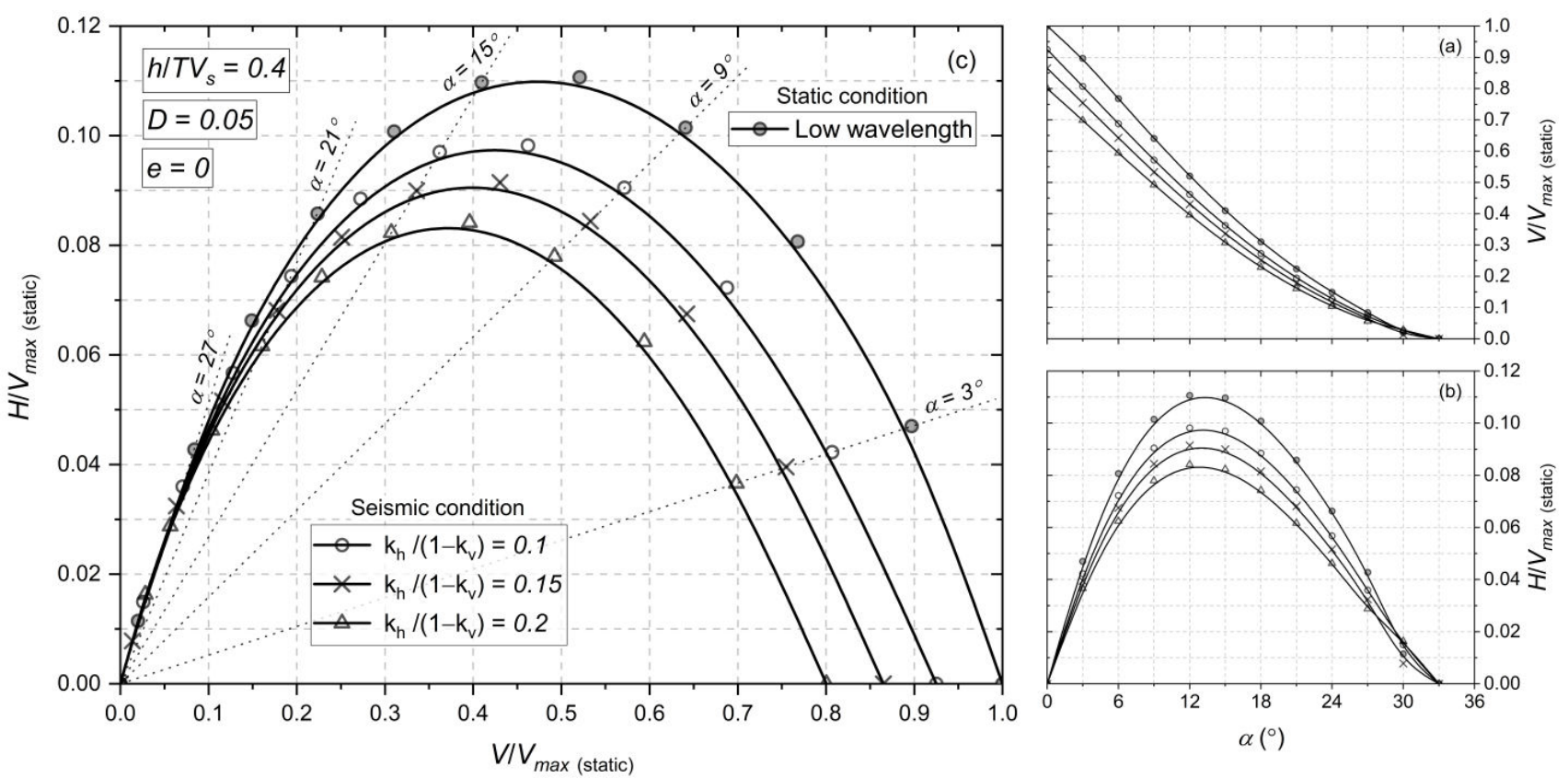

1002
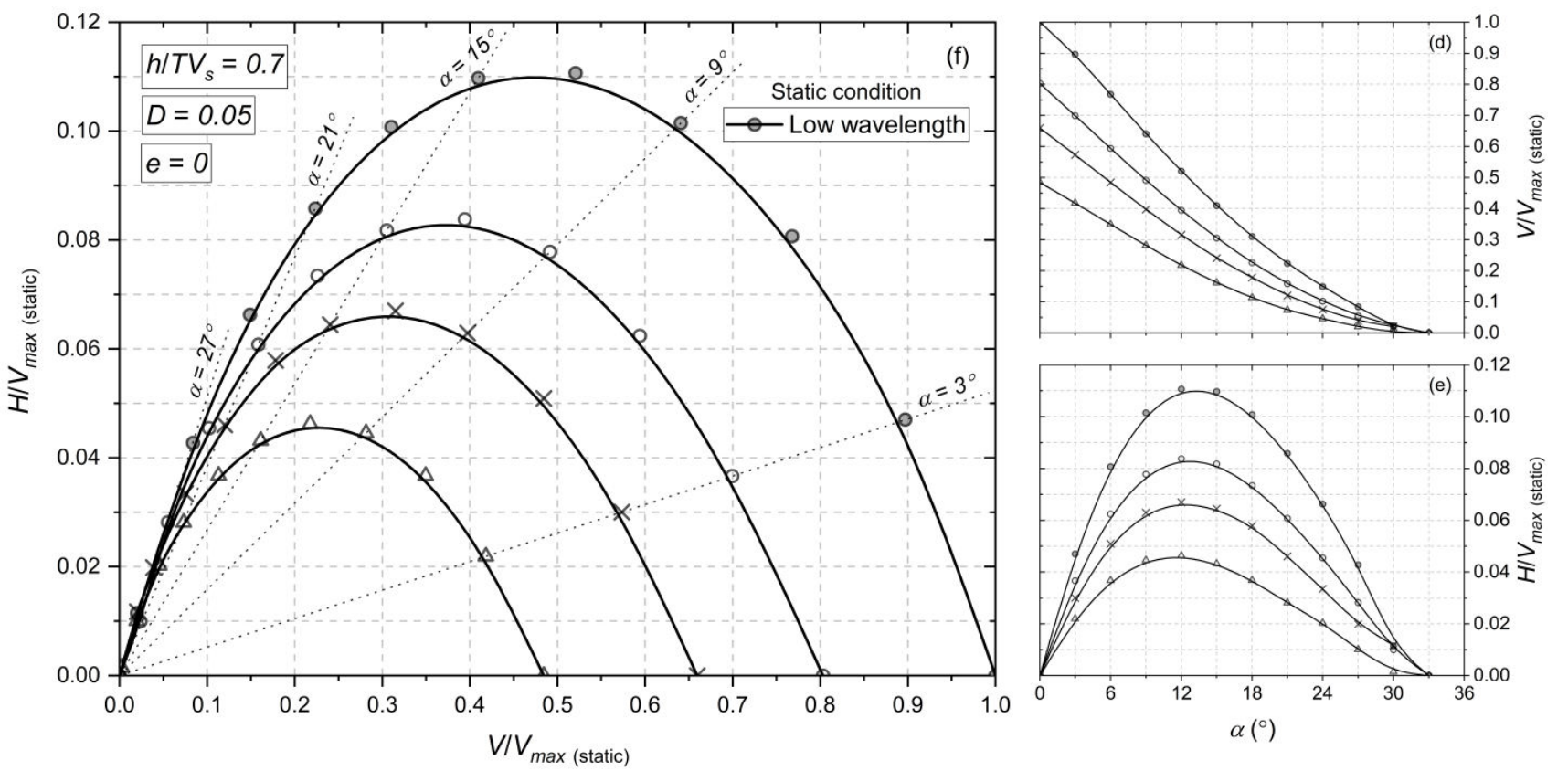

Fig. 7. Influence of seismic intensity $\left(k_{h} /\left(1-k_{v}\right)\right)$ on the failure envelope of obliquely-loaded shallow foundations subjected to a wide range of load inclinations $\left(h / T V_{s}=0.25, D=0.05\right)$ 

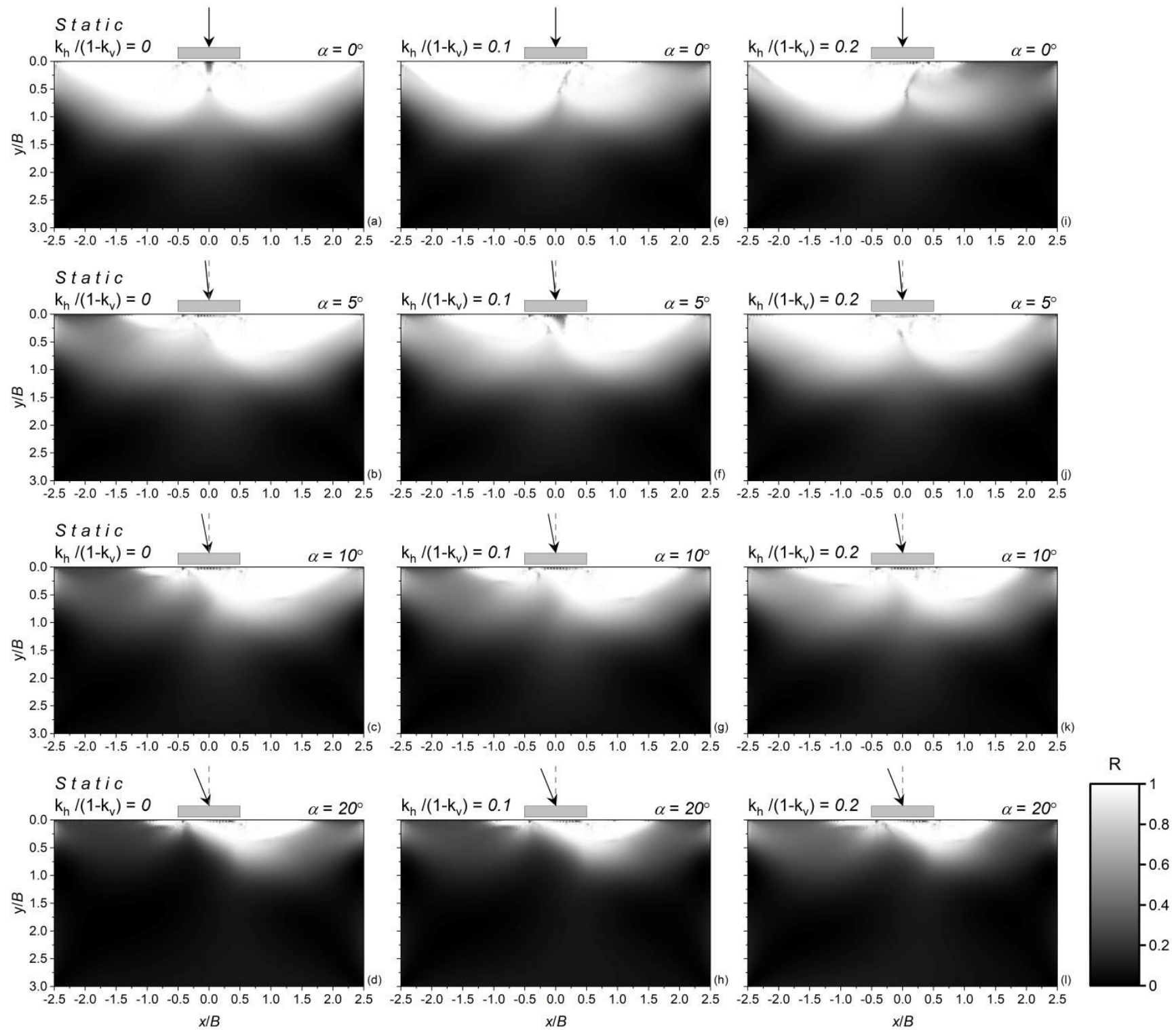

Fig. 8. Failure patterns of obliquely-loaded shallow foundations under static and pseudo-static loading 1015 conditions

1016

1017

1018

1019 

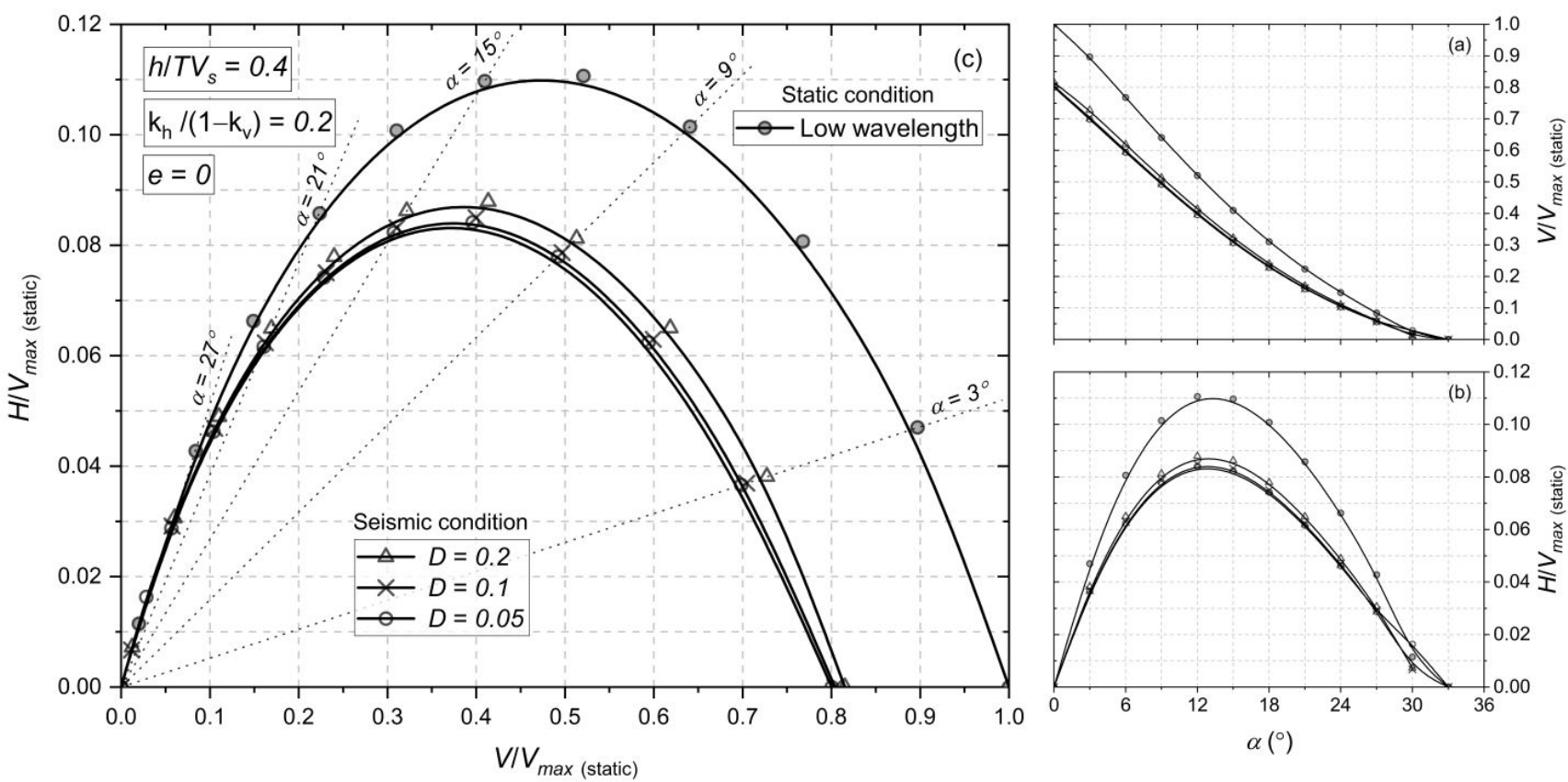

1029

1030

1031

1032

1033

1034

1035
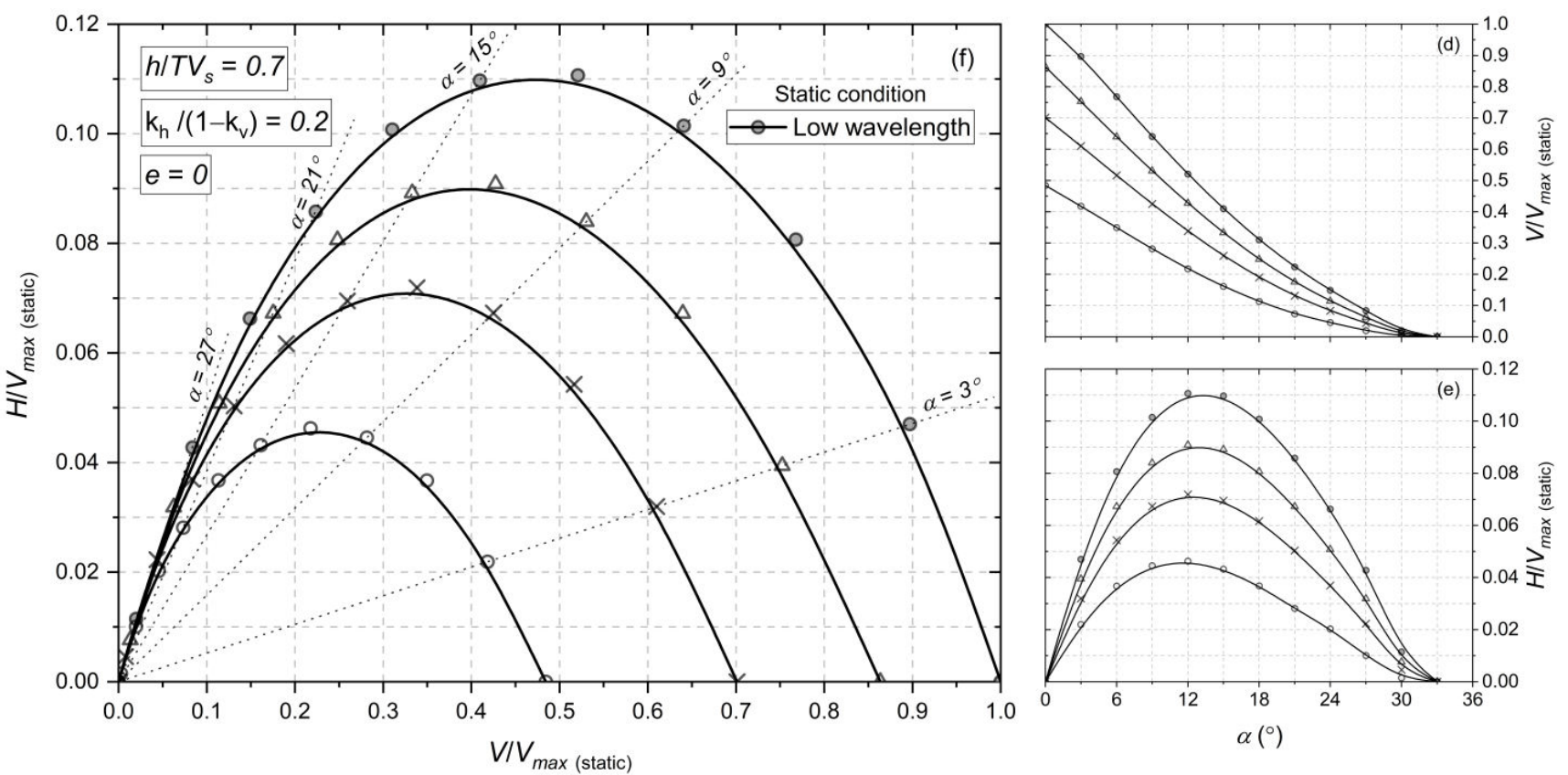

Fig. 9. Influence of material damping $(D)$ on the failure envelope of obliquely-loaded shallow foundations subjected to a wide range of load inclinations $\left(h / T V_{s}=0.25, k_{h} /\left(1-k_{v}\right)=0.2\right)$ 

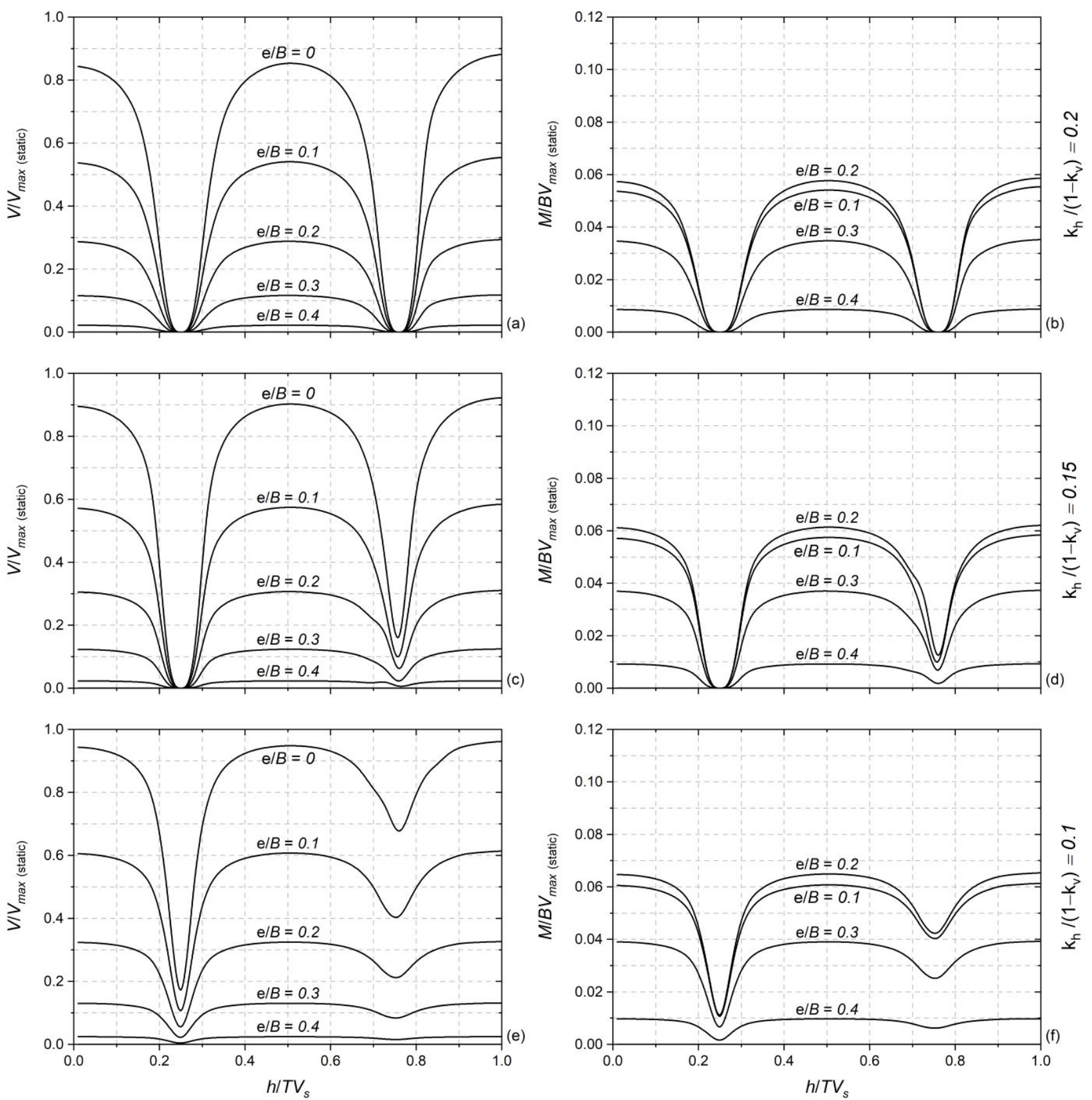

Fig. 10. Influence of seismic intensity $\left(k_{h} /\left(1-k_{v}\right)\right)$ on the modified pseudo-dynamic bearing capacity of eccentrically-loaded shallow foundations subjected to a wide range of load eccentricities $(D=0.05)$ 

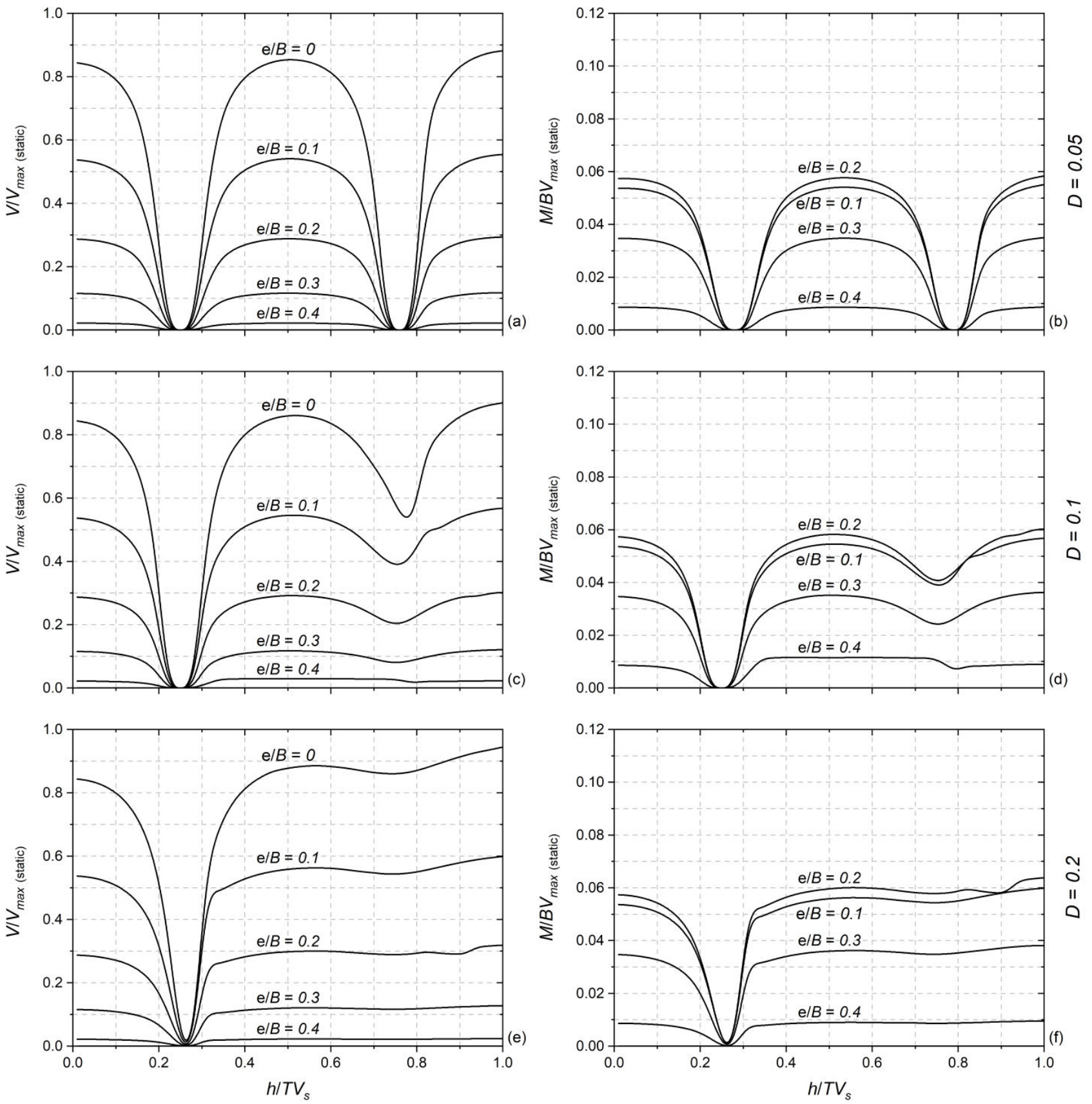

1046

Fig. 11. Influence of material damping $(D)$ on the modified pseudo-dynamic bearing capacity of eccentrically-loaded shallow foundations subjected to a wide range of load eccentricities $\left(k_{h} /(1-\right.$ $\left.\left.k_{v}\right)=0.2\right)$ 


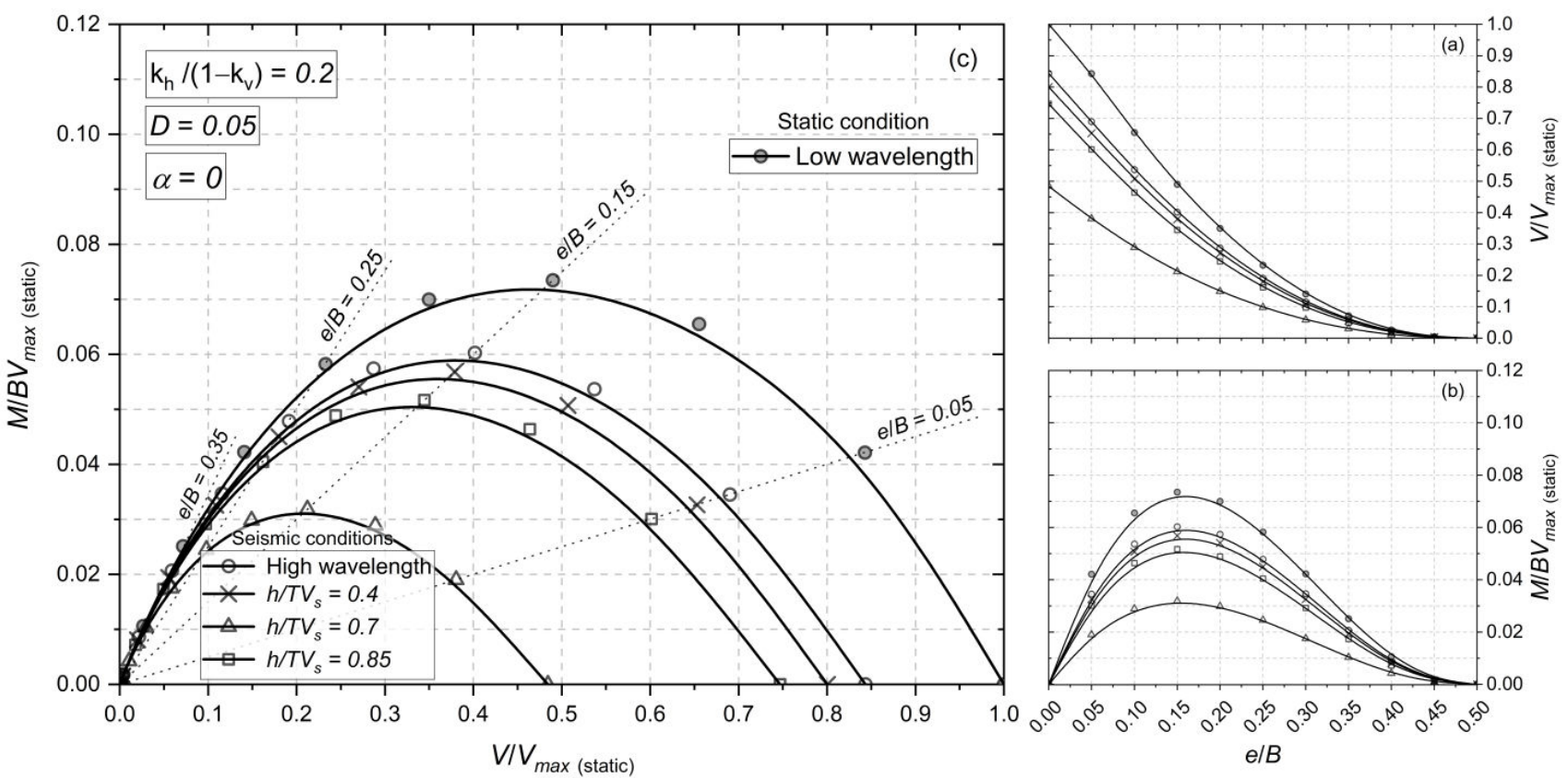

Fig. 12. Failure envelopes of eccentrically-loaded shallow foundations subjected to various nondimensional frequencies under a wide range of load eccentricities $\left(k_{h} /\left(1-k_{v}\right)=0.2, D=0.05\right)$ 


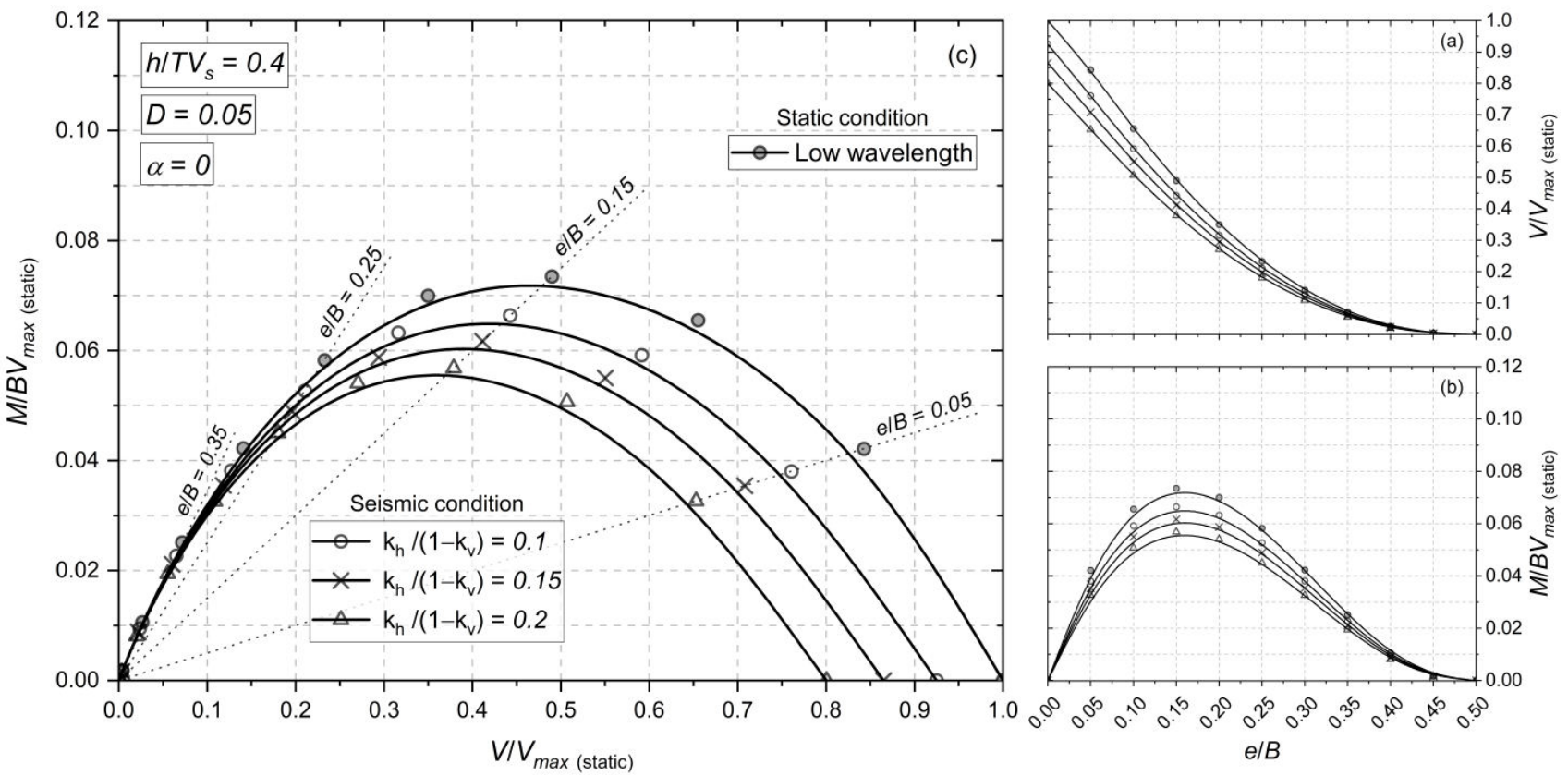

1078

1079
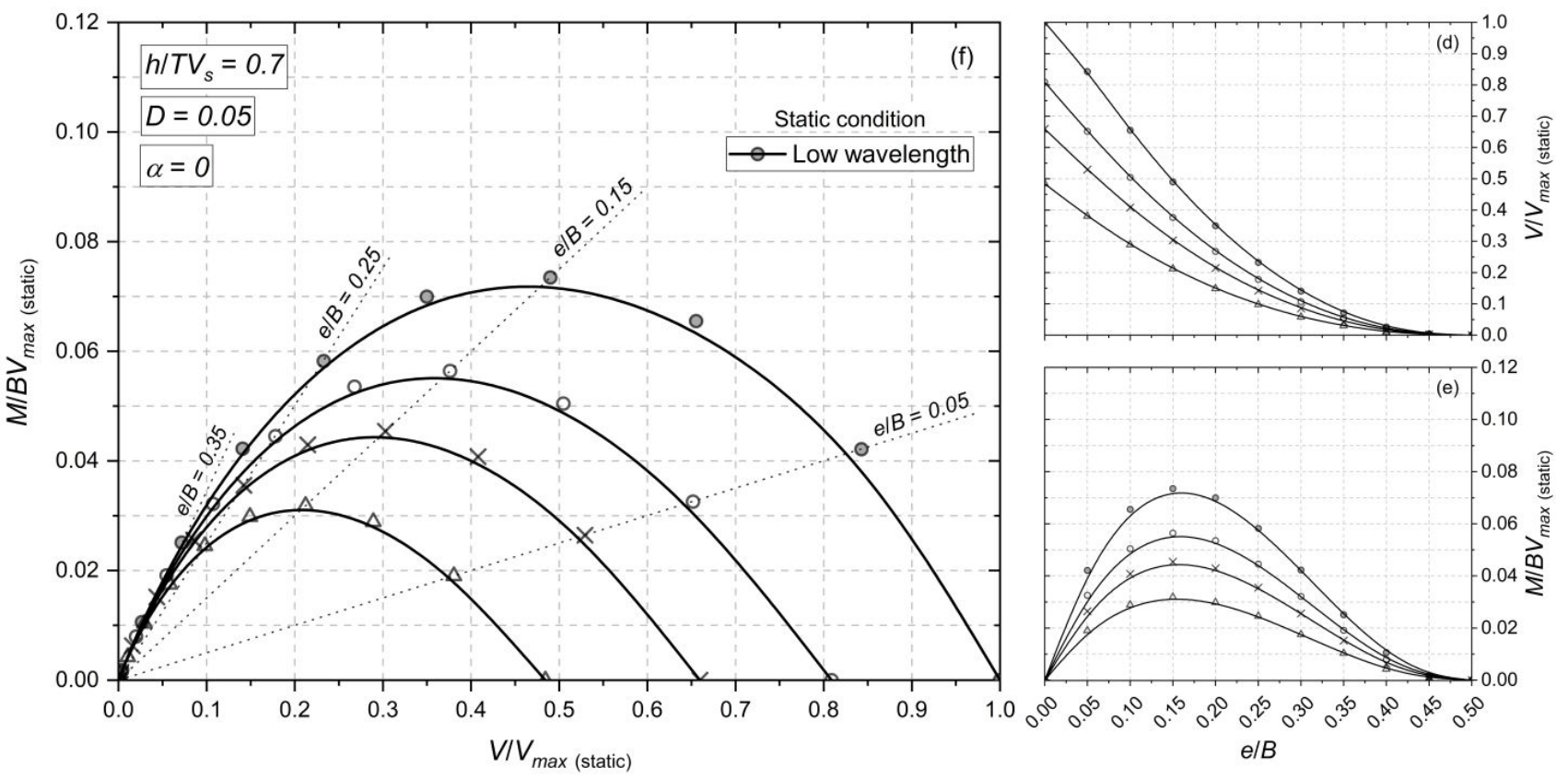

Fig. 13. Influence of seismic intensity $\left(k_{h} /\left(1-k_{v}\right)\right)$ on the failure envelope of eccentrically-loaded shallow foundations subjected to a wide range of load eccentricities $\left(h / T V_{s}=0.25, D=0.05\right)$ 

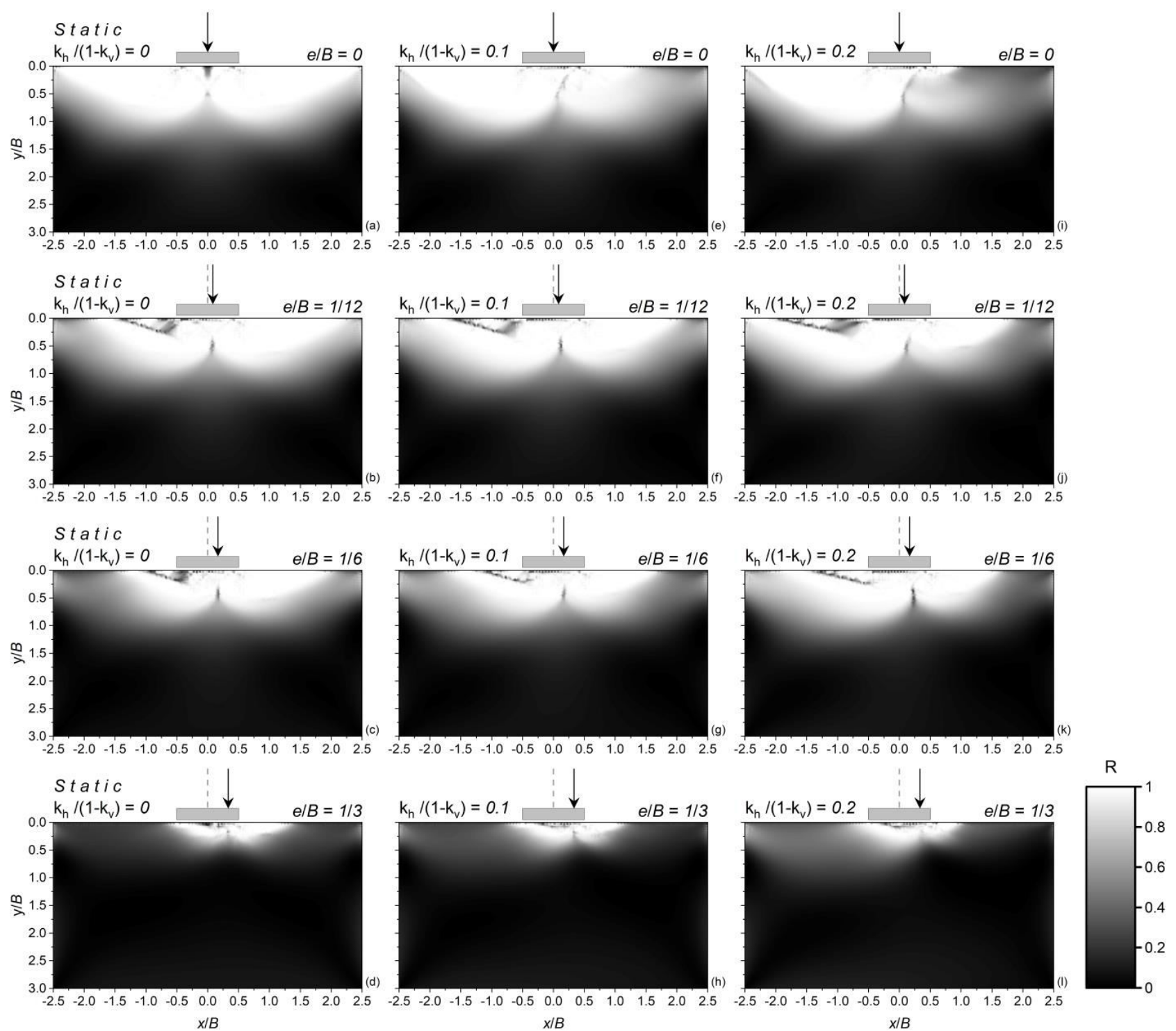

1093

Fig. 14. Failure patterns of eccentrically-loaded shallow foundations under static and pseudo-static loading conditions 


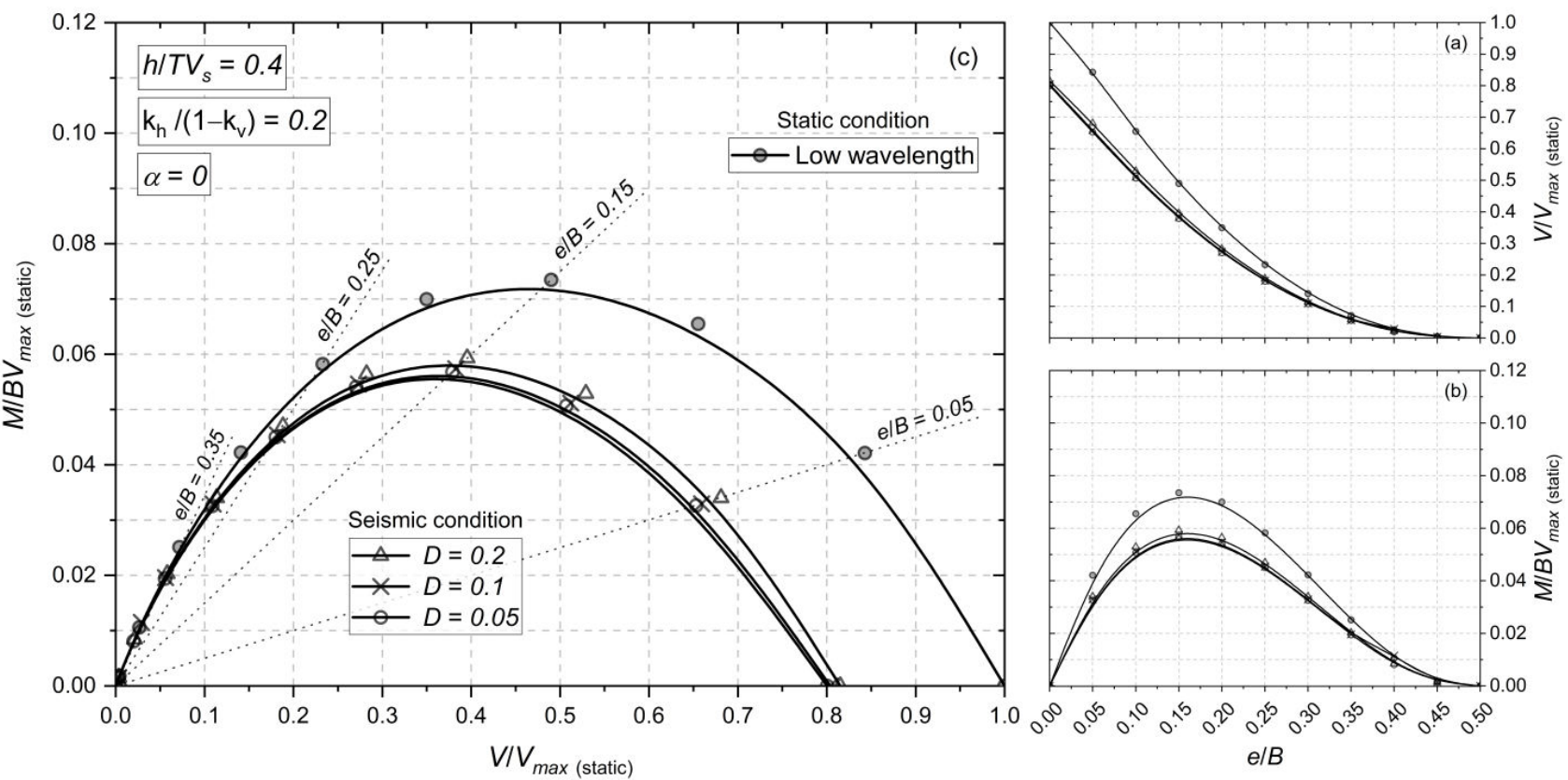

1103 $\max ($ static)
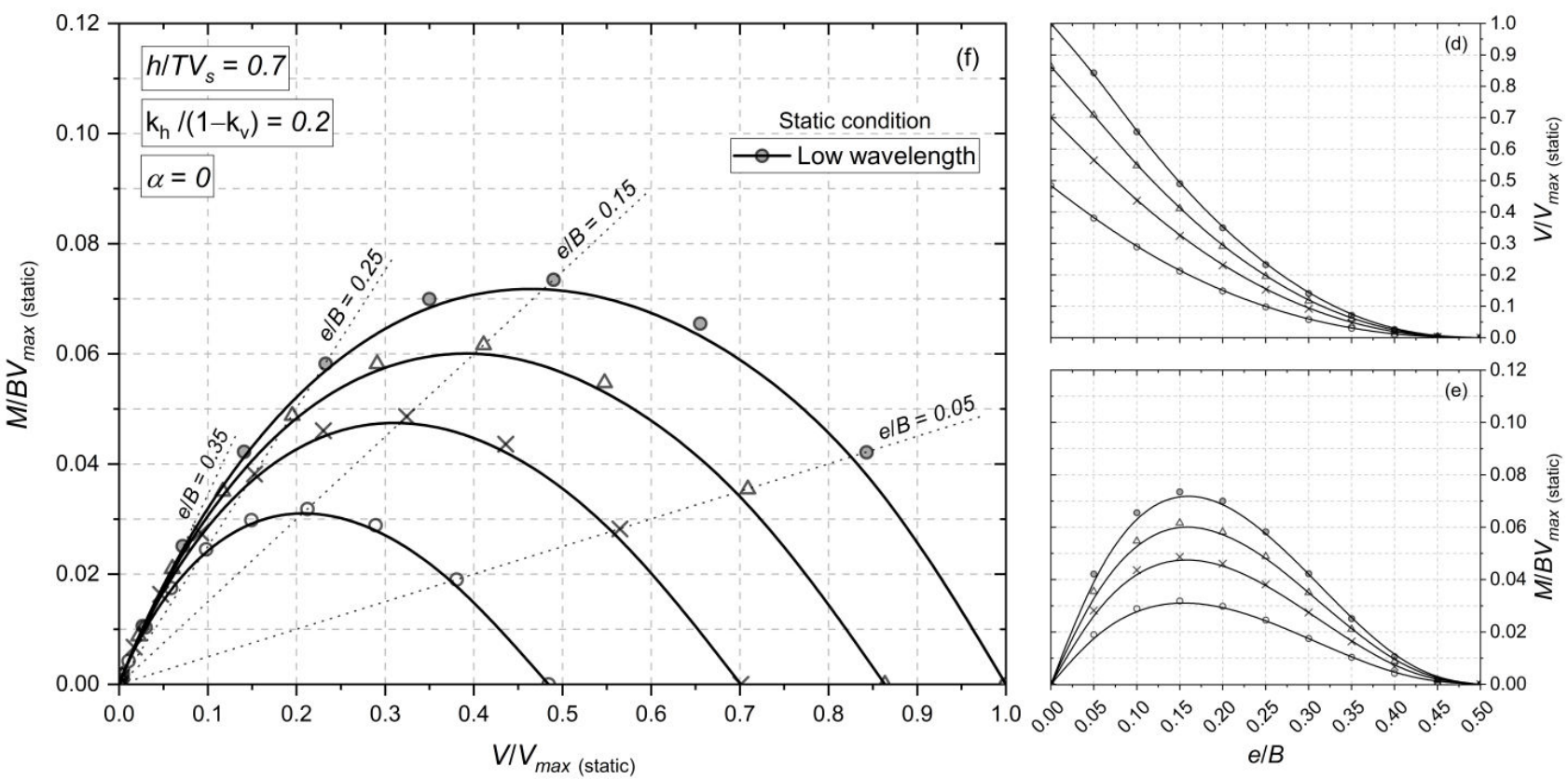

Fig. 15. Influence of material damping $(D)$ on the failure envelope of eccentrically-loaded shallow foundations subjected to a wide range of load eccentricities $\left(h / T V_{s}=0.25, k_{h} /\left(1-k_{v}\right)=0.2\right)$ 